\title{
Atomistic details of oxide surfaces and surface oxidation: the example of copper and its oxides
}

\author{
Chiara Gattinoni and Angelos Michaelides \\ Thomas Young Centre, London Centre for Nanotechnology and Department of Chemistry \\ University College London \\ 17-19 Gordon Street, London, WC1H 0AH, UK
}

\begin{abstract}
The oxidation and corrosion of metals are fundamental problems in materials science and technology that have been studied using a large variety of experimental and computational techniques. Here we review some of the recent studies that have led to significant advances in our atomic-level understanding of copper oxide, one of the most studied and better understood metal oxides. We show that a good atomistic understanding of the physical characteristics of cuprous $\left(\mathrm{Cu}_{2} \mathrm{O}\right)$ and cupric $(\mathrm{CuO})$ oxide and of some key processes of their formation has been obtained. Indeed, the growth of the oxide has been proven to be epitaxial with the surface and to proceed, in most cases, through the formation of oxide nano-islands which, with continuous oxygen exposure, grow and eventually coalesce. We also show how electronic structure calculations have become increasingly useful in helping to characterise the structures and energetics of various $\mathrm{Cu}$ oxide surfaces. However a number of challenges remain. For example, it is not clear under which conditions the oxidation of copper in air at room temperature (known as native oxidation) leads to the formation of a cuprous oxide film only, or also of a cupric overlayer. Moreover, the atomistic details of the nucleation of the oxide islands are still unknown. We close our review with a perspective on future work and discuss how recent advances in experimental techniques, bringing greater temporal and spatial resolution, along with improvements in the accuracy, realism and timescales achievable with computational approaches make it possible for these questions to be answered in the near future.
\end{abstract}

\section{Introduction}

Copper is a material which has accompanied human pre-history and history, and it is still highly relevant today. Cold working of copper has been performed for at least 10,000 years and smelting of copper ore for around 7,000 years ${ }^{11}$. Its use as construction materials, e.g. in piping, can be dated back to ancient Egypt, and its importance in this field has not diminished nowadays. In the modern world it has acquired further uses, for example in electrical systems and electronic devices.

Within this long history, the properties of copper have been extensively studied and exploited, however much is still unknown about this important metal. In particular, the oxidation and corrosion of copper, which impacts its performance in industrial and technological applications, is still not completely understood.

Copper is found to readily oxidise at room temperature 2 , and the presence of an oxide layer, however thin, can compromise its uses in technology. As an example, copper could be an environmentally friendly and low-cost substitute for the (currently used) tin-lead or (promising) gold- and silver-based solder alloys in electronic packaging, if there was a way to prevent its oxidation ${ }^{5}$. Moreover, copper canisters are used for nuclear waste disposal, and understanding the oxidation and corrosion of copper in anaerobic conditions is thus really important ${ }^{6}$. On the other hand, the existence of stable copper oxides at room temperature, with $\mathrm{a} \sim 2.0 \mathrm{eV}$ band gap, makes them interesting for catalytic ${ }^{7}$, gas 
sensing ${ }^{8}$, optoelectronic and solar technologies $\frac{910}{}$. Thus, there currently is a two-fold interest in understanding copper oxides: from the one hand, to mitigate against technological failure, on the other hand, to exploit their potential industrial applications.

Copper is considered a model system to understand the formation of metal oxides in general. The atomistic details of the oxidation process tend to be system-specific, with some metals showing uniform oxide growth (e.g. Ref. 11 ), other complex temperature-dependent phenomena such as surface roughening (e.g. Ref. ${ }^{[12}$ ) and island formation (e.g. Ref. ${ }^{13235}$ ). However, the copper oxidation process is one of the most studied with a large number of experimental and computational methods, and one of the better understood. Therefore, a detailed understanding of copper oxidation, of the techniques used to study it and of the challenges which are still open is invaluable when considering the oxidation process on any other system.

In this review, we discuss the status of knowledge of copper oxidation from the atomistic point of view, which we believe is of key importance if we want to learn how to prevent or manipulate copper oxidation. We cannot hope to provide a complete review of all the work done on this subject since the beginning of the last century 14 . We are therefore only going to focus on recent surface science, spectroscopy and atomistic computational work which has been performed to understand the properties of copper oxides and their formation, and on the open challenges that can be addressed using these techniques.

First, a brief overview on the experimental and computational techniques which have been used for the study of oxide structures and oxidation kinetics is given (Sec. 2), in order to clarify some of the terminology used throughout the review. The structural and electronic characteristics of the bulk oxides and their surfaces are then presented (Sec. 3). We subsequently look at the interaction of clean copper surfaces with oxygen and the initial stages of controlled oxidation (Sec. 4) as well as long-term oxidation (Sec. 5). Finally, in Sec. 6, conclusions and perspectives are given.

We hope that it will be clear from the following that tremendous progress has been made in understanding the atomistic details of copper oxides and their formation under different conditions. However, equally important gaps in our understanding remain, especially in terms of the formation kinetics and the structure of the resulting oxide surfaces.

\section{Experimental and computational techniques}

An enormous number of experimental $\sqrt{17}+20$ and computational techniques are available to investigate the physical and chemical characteristics of solids, surfaces and surface kinetic processes. Many of them have been used over the years to e.g., understand oxide structures, characterize oxide surfaces, understand the oxidation kinetics and investigate bulk properties of the oxides. For clarity, in this section we provide a brief introduction to the most relevant techniques which have been used on copper oxide and which are going to be mentioned in the following sections, with an emphasis on strengths and weaknesses of each approach.

In early studies of oxidation, thermogravimetric analysis (TGA), where changes in physical and chemical properties of materials are measured as a function of time, has been widely used to study the onset of oxidation by recording the mass gain of a sample under oxygen exposure. Whilst useful in providing a broad overview of the extent of oxidation, this technique is however unable to provide atom-resolved information.

Imaging techniques such as electron microscopy (EM), transmission electron microscopy (TEM) and their derivatives (e.g., high-resolution transmission electron microscopy (HRTEM) or field emission scanning electron microscopy (FESEM)) and surface-specific techniques such as scanning tunnelling microscopy (STM) can be applied to surfaces and provide atomistic level structural information. As we will see, they have been amply used to image adsorption of oxygen on the copper surface, surface reconstructions and initial oxide formation. The atomic composition and oxidation states of the atoms 
in a material can be obtained using spectroscopic techniques such as X-ray diffraction (XRD), Auger electron spectroscopy (AES), electron energy loss spectroscopy (EELS), low-energy electron diffraction (LEED), reflection high-energy electron diffraction (RHEED), X-ray photoelectron spectroscopy (XPS or ESCA) and X-ray absorption spectroscopy (XAS). The space- and time-resolution of these techniques has greatly improved since they were first used in this field (in the 1980s), as well as their range of applicability: for example, experiments at relatively high pressures can be performed nowadays ${ }^{\text {. }}$.

Growth of the oxide and its atomic composition has been extensively studied by means of ellipsometry. This technique measures changes in polarization as light interacts with an object and the resulting data are fitted with a 'guess' model for the material (e.g. a two-layer $\mathrm{Cu}_{2} \mathrm{O} / \mathrm{Cu}$ model or a three-layer $\mathrm{CuO} / \mathrm{Cu}_{2} \mathrm{O} / \mathrm{Cu}$ one).

Computer simulations have also been widely applied to study the structural, optical and vibrational characteristics of copper oxides. When carrying out simulations of materials at the atomic scale, classical empirical potentials (force fields) or more sophisticated quantum ( $a b$ initio) approaches, such as density functional theory (DFT), can be used. Force fields are parametrised empirical potentials tuned to reproduce the interactions of the atoms in the system at hand. For certain problems force fields can provide a faithful description. However, the reliability and transferability of such calculations depends primarily on the extent and quality of the data used in their construction. Moreover, force fields cannot generally be applied to study chemical reactions. Current development in force fields are addressing these issues. Indeed, parametrisations obtained by fitting large data sets using e.g., neural network ${ }^{22}$ and machine learning methods 23 , to name just two, are improving accuracy and transferability. Moreover, bond order potentials (such as ReaxFF ${ }^{24}$ ) and polarisable force fields ${ }^{\sqrt{25}}$ are making it possible to simulate chemical reactions. It is difficult to make general statements about the sizes of systems that can be explored with various methods. However, with many standard force fields it is now possible to examine systems with $\sim 100,000$ atoms on a routine basis. In addition, it is possible to explore the evolution of a system of this size, again on a routine basis, with an approach such as molecular dynamics for several hundreds of nanoseconds.

More accurate approaches are $a b$ initio methods which aim to study the structure and properties of a material by seeking (approximate) solutions to quantum mechanical equations such as the manyelectron, many-atom Schroedinger equation. These methods are more general and do not require system-specific parametrisations, however they are computationally more expensive. One of the most widely used methods to study the properties of bulk materials and surfaces is density functional theory $(\mathrm{DFT})$ 27 30. With DFT it is possible to make genuine predictions about structural properties of a material within a few percent of the experimental value. DFT also provides access to the electronic structure of the systems being considered and related spectroscopic properties. In DFT, the energy of the electronic system is determined from the electronic density by solving Schroedinger-like equations. Whilst exact in principle, in practice approximations have to be introduced since the functional form of the electron-electron interaction, called the exchange-correlation (XC) functional, is unknown. Many approximate $\mathrm{XC}$ functionals have been developed ${ }^{31}$, the most common ones being the local density approximation (LDA) and the generalised gradient approximation (GGA). A number of deficiencies in DFT arise from these approximations and the choice of an appropriate $\mathrm{XC}$ functional is critical in order to obtain meaningful results. As an example, in strongly correlated systems like $\mathrm{CuO}$ (typically, where $d$ and $f$ orbitals are localised), the GGA and LDA functionals provide a poor description of the electronic and bulk crystal structure. Moreover, the band gap obtained using GGA or LDA in semiconductors or insulators is generally underestimated. In these cases it is possible to add simple but somewhat ad hoc corrections to the functionals (e.g. the Hubbard $\mathrm{U}^{32}$, self-interaction correction $\mathrm{SIC}^{33}$ ) or to use more sophisticated hybrid functionals (e.g. HSE06 $6^{34}, \mathrm{PBE} 0^{35}$ ) which incorporate some exact Hartree-Fock exchange. Compared to standard empirical potential methods, DFT is much more computationally demanding, and, on a routine basis, systems with only a few 100 atoms can be examined and the dynamics of such systems explored for only a few tens of picoseconds. 

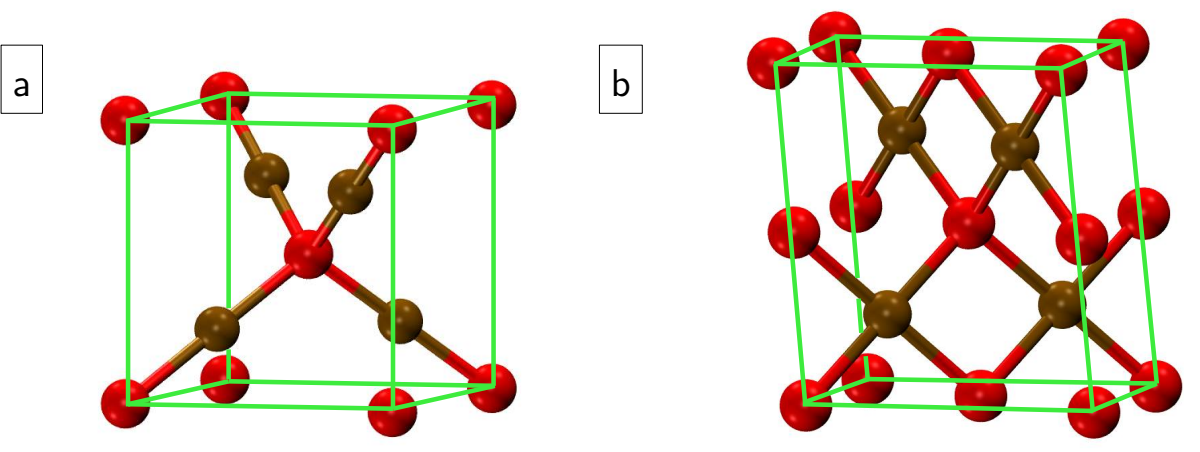

Figure 1: Ball-and-stick model of a unit cell of a) cuprous oxide $\mathrm{Cu}_{2} \mathrm{O}$ and b) cupric oxide $\mathrm{CuO}$. Red balls represent oxygen and brown balls copper. The unit cell is shown in green.

Other computational methods which have been used in copper oxide simulations are the GW $\operatorname{method}^{[36}$, used when optoelectronic properties are of interest, since it is more accurate at predicting band structures than standard DFT XC functionals. In addition there have been a number of HartreeFock ${ }^{37}$ studies and calculations with simpler approaches, such as the linear combination of atomic orbitals (LCAO) and tight binding methods 38 .

\section{Oxide structures}

We are going to introduce here the bulk and surface structures of the two main copper oxides, $\mathrm{Cu}_{2} \mathrm{O}$ and $\mathrm{CuO}$. Knowledge of the physical properties of these materials, and especially of the surface structures, is relevant background when trying to understand the formation and growth of the copper oxide.

The two most common forms of the oxide (shown in Fig. 1) are cuprite (or cuprous oxide, $\mathrm{Cu}_{2} \mathrm{O}$ ), the principal oxide at low temperatures and pressure, and tenorite (or cupric oxide, $\mathrm{CuO}$ ), dominant at high temperatures and pressures 39 . Another copper oxide structure, paramelaconite $\left(\mathrm{Cu}_{4} \mathrm{O}_{3}\right)$, exists as a rare mineral found in hydrothermal deposits of copper. Cuprite has long been known to be the primary oxide for copper at ambient conditions and there is considerable interest in its application to catalysis, optoelectronics and gas sensing and therefore a large amount of work has been done to determine its physical and chemical characteristics. Tenorite has been studied less and still relatively little is understood about the structure of its surfaces, with only a handful of experimental and computational studies performed to that aim.

\section{1 $\quad \mathrm{Cu}_{2} \mathrm{O}$ bulk properties}

In cuprous oxide $\left(\mathrm{Cu}_{2} \mathrm{O}\right.$, see Fig. 1 1 a), a cubic crystalline solid, copper has a $\mathrm{Cu}^{1+}$ oxidation state. It is a $p$-type semiconductor with a direct band gap of $2.02-2.17 \mathrm{eV}$ and an optical gap of $2.62 \mathrm{eV} 10 / 40 / 41$. It is a promising material for a variety of industrial applications because of its band gap and because it shows negative thermal expansion $\underline{42143}$.

The properties of cuprous oxide have been extensively studied using empirical potentials $\frac{44}{4}$, tight binding $\frac{45}{4}$ and $a b$ initio methods. Ab initio studies include the use of DFT methods (see Table 1), and good agreement with the experimental bulk structure (i.e. no more than $2.5 \%$ discrepancy between the calculated and experimental value of the lattice constant) and vibrational modes ${ }^{46}$ have been found. However, the band gap is underestimated with standard DFT XC functionals, yielding values between 


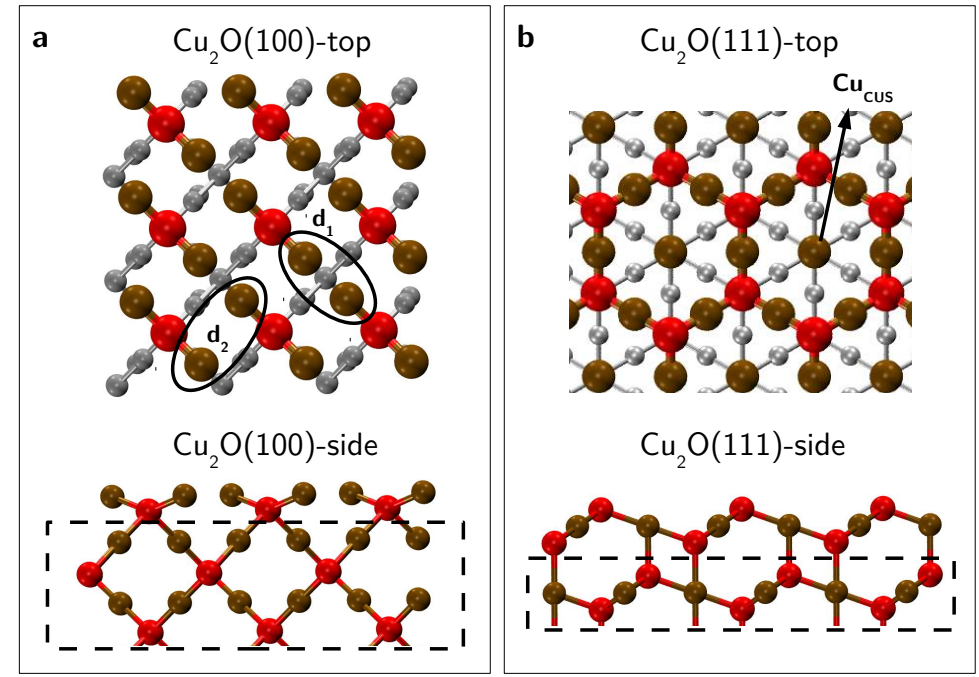

Figure 2: Structure of the $\mathrm{Cu}$-terminated $\mathrm{Cu}_{2} \mathrm{O}(100)$ and O-terminated $\mathrm{Cu}_{2} \mathrm{O}(111)$ surfaces. $\mathrm{O}$ atoms are shown in red and $\mathrm{Cu}$ atoms in brown. Atoms below the surface layer are depicted in grey in the top views and enclosed in a box in the side views. a) Top and side view of a copper terminated $\mathrm{Cu}_{2} \mathrm{O}(100)$ slab, consisting of alternating layers of $\mathrm{O}$ and $\mathrm{Cu}$ atoms. The surface copper atoms 'sink' towards the $\mathrm{O}$-atoms plane and form $\mathrm{Cu}-\mathrm{Cu}$ dimers (indicated by $\mathrm{d} 1$ ). The second dimer formed in order to obtain the $(3 \sqrt{2} \times \sqrt{2}) R 45^{\circ}$ reconstruction is labelled $\mathrm{d} 2$. b) Top and side view of the O-terminated $\mathrm{Cu}_{2} \mathrm{O}(111)$ surface. One $\mathrm{O}-\mathrm{Cu}-\mathrm{O}$ trilayer is shown between the dashed lines in the side view. The surface layer presents a hexagonal structure with an unsaturated copper atom $\mathrm{Cu}_{\mathrm{Cus}}$ in the middle of each hexagon.

0.5 and $0.8 \mathrm{eV}^{47-49}$ and grossly overestimated with Hartree-Fock methods at $9.7 \mathrm{eV}[50$. Corrections to DFT (e.g. DFT+U or the GW approximation applied to DFT-GGA) give rise to band gaps that are in better agreement with experiment $\sqrt[51+56]{56}$, as summarised in Table 1 .

\section{$3.2 \mathrm{Cu}_{2} \mathrm{O}$ surfaces}

Experimental data are available only for $\mathrm{Cu}_{2} \mathrm{O}(100)$ and $\mathrm{Cu}_{2} \mathrm{O}(111)$ low index surfaces of cuprous oxide, by means of XPS (which monitors the $\mathrm{Cu}$ to $\mathrm{O}$ ratio on the surface), LEED in ultra high vacuum (which identifies the periodicity of the surface), and in the case of $\mathrm{Cu}_{2} \mathrm{O}(111)$, also with TEM.

We first consider the polar $\mathrm{Cu}_{2} \mathrm{O}(100)$ surface, which is formed by a succession of purely $\mathrm{Cu}$ or $\mathrm{O}$ layers and yields bulk-truncated surfaces which are either O- or Cu-terminated (Fig. 2a). Polar surfaces generally reconstruct $\frac{69}{6}$ and three different reconstructions were observed on $\mathrm{Cu}_{2} \mathrm{O}(100)$ according to the preparation method 70 . The most stable surface in vacuum is a $\mathrm{Cu}$-terminated surface with a $(3 \sqrt{2} \times \sqrt{2}) R 45^{\circ}$ reconstruction. The LEED pattern (which however showed many missing spots and the reconstruction is presented as tentative) was interpreted as a relaxation of the top layer of copper cations forming two surface dimers (d1 and d2 in Fig. 2a). Two transient structures were also identified: at $900 \mathrm{~K}$, a $(\sqrt{2} \times \sqrt{2}) R 45^{\circ}$ reconstruction presenting a $1 / 2$ layer of terminal oxygen, and, after long oxygen exposures, the stoichiometric $(1 \times 1)$ O-terminated surface. Both structures revert to the $(3 \sqrt{2} \times \sqrt{2}) R 45^{\circ}$ reconstruction upon further annealing over $500 \mathrm{~K}$. The $(3 \sqrt{2} \times \sqrt{2}) R 45^{\circ}$ reconstruction has been reproduced computationally $\underset{71}{ }$, and it is more stable than the $\mathrm{Cu}-$ or $\mathrm{O}$ terminated $(\sqrt{2} \times \sqrt{2}) R 45^{\circ}$ reconstruction $\underline{63|72| 73 \text {. }}$.

The other experimentally studied surface is $\mathrm{Cu}_{2} \mathrm{O}(111)$. A $\mathrm{Cu}_{2} \mathrm{O}(111)$ slab is formed by a succession of $\mathrm{O}-\mathrm{Cu}-\mathrm{O}$ trilayers, ending with either a (stoichiometric, non polar) oxygen or (non-stoichiometric) copper termination (Fig. 2b). Photoemission and LEED experiments on this $\mathrm{Cu}$-terminated (111) 


\begin{tabular}{|c|c|c|c|c|}
\hline Ref. & $a[\AA]$ & $B[\mathrm{GPa}]$ & $\begin{array}{l}\text { Band gap } \\
{[\mathrm{eV}]}\end{array}$ & $\mathrm{XC}$ \\
\hline Cortona & 4.221 & 141 & - & $\mathrm{LDA}$ \\
\hline Filippetti ${ }^{53}$ & 4.23 & - & 0.55 & LDA \\
\hline Gordienko 58 & 4.2696 & - & 2.87 & LDA \\
\hline $\mathrm{Nie}^{59}$ & 4.216 & - & 0.52 & LDA \\
\hline Heinemann 60 & 4.1656 & - & 0.99 & $\mathrm{LDA}+\mathrm{U}(\mathrm{U}-\mathrm{J}=6.52)$ \\
\hline $\operatorname{Tran} 61$ & $4.27^{*}$ & - & $0.63-0.94$ & $\mathrm{LDA}+\mathrm{U}(3<\mathrm{U}-\mathrm{J}<11)$ \\
\hline Cortona ${ }^{57}$ & 4.359 & 106 & - & $\mathrm{PBE}$ \\
\hline Islam 47 & 4.312 & - & 0.7 & $\mathrm{PBE}$ \\
\hline Isseroff 62 & 4.18 & 145 & 0.68 & LDA \\
\hline Isseroff 62 & $4.10-4.17$ & $135-143$ & $0.81-1.15$ & $\mathrm{LDA}+\mathrm{U}(2<\mathrm{U}-\mathrm{J}<8)$ \\
\hline Isseroff 62 & 4.31 & 109 & 0.43 & GGA \\
\hline Isseroff 62 & $4.26-4.30$ & $96-106$ & $0.54-0.84$ & GGA $+\mathrm{U}(2<\mathrm{U}-\mathrm{J}<8)$ \\
\hline Isseroff 62 & 4.28 & 114 & 2.84 & PBE0 \\
\hline Isseroff 62 & 4.29 & 114 & 2.04 & HSE \\
\hline $\mathrm{Le}^{63}$ & 4.317 & - & - & $\mathrm{PBE}$ \\
\hline $\begin{array}{l}\text { Martinez- } \\
\text { Ruiz }^{48}\end{array}$ & 4.3 & 108 & 0.5 & $\mathrm{PBE}$ \\
\hline Bohnen $\underline{42}$ & 4.30 & 112 & - & $\mathrm{PBE}$ \\
\hline Soon 64 & 4.34 & 104 & - & $\mathrm{PBE}$ \\
\hline Soon ${ }^{49]}$ & 4.32 & 104 & 0.64 & PBE \\
\hline Ruiz & 4.435 & 100 & 9.7 & $\mathrm{HF}$ \\
\hline Ruiz & 4.277 & 93 & - & $\mathrm{HF}+\mathrm{LYP}$ \\
\hline Heinemann & 4.2675 & - & 2.02 & HSE06 \\
\hline Scanlon 65 & - & - & 2.12 & HSE \\
\hline $\operatorname{Tran} 61$ & $4.27^{*}$ & - & $0.79-2.77$ & PBE0 \\
\hline Bruneval 66 & - & - & 1.34 & $\mathrm{G}_{0} \mathrm{~W}_{0}$ \\
\hline Bruneval 66 & - & - & 1.97 & scGW \\
\hline Filippetti & 4.23 & - & 1.8 & SIC \\
\hline Kotani 67 & - & - & 1.97 & scGW \\
\hline Lany 68 & - & - & 2.03 & $\mathrm{GW}+\mathrm{V}_{d}$ \\
\hline Experiment 1040 & 4.27 & $106-138$ & $2.02-2.17$ & - \\
\hline
\end{tabular}

Table 1: Summary of the calculated lattice constant $a$, bulk modulus $B$ and band gap for $\mathrm{Cu}_{2} \mathrm{O}$. Information on the exchange-correlation (XC) functional is also given. PBE is a type of GGA functional. scGW, G0W0 and GW $+\mathrm{V}_{d}$ are different applications of the GW method. HF+LYP is a Hartree-Fock type calculation with an a posteriori correction using the LYP correlation functional. For calculations using the $+\mathrm{U}$ Hubbard correction, values of the relevant parameters used (U-J) are given ion eV units. *These calculations were performed at the experimental value of the lattice constant. 
surface found, after annealing in UHV, a nearly stoichiometric reconstruction, with $(\sqrt{3} \times \sqrt{3}) R 30^{\circ}$

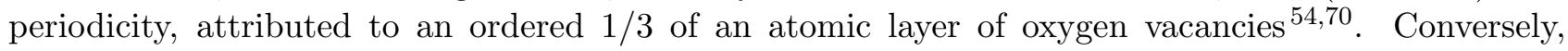
annealing in oxygen gives a stoichiometric oxygen-terminated surface (with possibly the loss of the unsaturated copper atoms, $\mathrm{Cu}_{C U S}$ in Fig. $2 \mathrm{~b}$, at the centre of the hexagons) ${ }^{54}$. The stability of both polar and non-polar stoichiometric $\mathrm{Cu}_{2} \mathrm{O}(111)$ surfaces has been studied also computationally $\underline{47 / 74}, 78$ by means of DFT combined with, in some cases, ab initio thermodynamics. Ab initio thermodynamics (see e.g. ${ }^{79 / 80}$ ) is a technique which allows one to estimate relative system stabilities in different environments; in this case, the stability of different oxide surfaces at a range of temperatures and oxygen partial pressures. These studies showed that the experimentally observed $\mathrm{Cu}_{2} \mathrm{O}(111)$ surfaces are indeed the most stable. 76 .

A wider range of low-index surfaces has been probed using DFT methods than experimentally 77 . The predicted lowest energy structure in high $\mathrm{O}_{2}$ pressure is the already mentioned $\mathrm{Cu}_{2} \mathrm{O}(111)$ surface missing the unsaturated $\mathrm{Cu}_{C U S}$ atom and at low $\mathrm{O}_{2}$ pressure the $\mathrm{Cu}_{2} \mathrm{O}(110)$ surface with a CuO-like surface reconstruction, which has not been observed experimentally (the (110) surface has not been studied yet).

It is thus evident that there is scope for further experimental work on this topic, to confirm the computational predictions or to propose new reconstructions. Surface-sensitive techniques such as STM and LEED, which allow a direct imaging of the surfaces, would be best suited to this aim. Moreover, theoretical methods would be well suited to understand the reason behind the transitions between different reconstructions at different conditions of temperature and pressure.

\section{$3.3 \quad \mathrm{CuO}$ bulk properties}

In $\mathrm{CuO}$, the copper atom has oxidation state $\mathrm{Cu}^{2+}$. The unit cell has monoclinic symmetry ${ }^{81}$ (see Fig. 1) and it contains four $\mathrm{CuO}$ dimers in the crystallographic unit cell, and two $\mathrm{CuO}$ units in the primitive cell. Each copper atom is located in the centre of an oxygen parallelogram. Each oxygen atom, in turn, has a distorted tetrahedral copper coordination. $\mathrm{CuO}$ is a $p$-type semiconductor 82 and it is antiferromagnetic in its ground state 86 .

From a DFT point of view, standard XC functionals alone are not accurate enough to reproduce the distorted nature of the lattice, and, upon structural relaxation, they produce an orthorhombic rather than a monoclinic structure $\sqrt{90}$. However, the use of more sophisticated functionals $52[60 \mid 90,93$ allows for the reproduction of the triclinic structure and good agreement with experiments on structural and vibrational data $\underline{94}$ (see Table 2).

The research focus for $\mathrm{CuO}$ has been for a long time on its optical properties, for phototermal and photoconductive applications, and on magnetic and phase stability properties, for possible hightemperature superconducting applications. The electronic properties of $\mathrm{CuO}$, instead, have been studied only more recently. The band gap of $\mathrm{CuO}$ has been experimentally measured to be $1.2-1.9$ $\mathrm{eV} 10$ |41|84|85|104, with the results depending on the sample preparation and on the measurement techniques used. Computationally, the band gap is well reproduced with the LDA+U approach (see Table 2), however the results depend strongly on the value of $\mathrm{U}$ while the HSE06 hybrid functional overestimates the gap by approximately $1 \mathrm{eV} 60$.

\section{4 $\mathrm{CuO}$ surfaces}

The potential use of $\mathrm{CuO}$ nanostructures for catalysis, sensing or superhydrophobicity and many other applications ${ }^{106}$ requires a good knowledge of the surfaces involved in these processes. Only one experimental study has been performed to date on $\mathrm{CuO}$ surfaces. In this work, it was found, using LEED, that the $\mathrm{CuO}(100)$ surface in UHV conditions does not present a reconstruction 107 .

DFT studies (using a GGA XC functional with the Hubbard U correction combined, in some cases, with ab initio thermodynamics) of the stoichiometric and of some defective surfaces have been 


\begin{tabular}{|c|c|c|c|c|c|}
\hline Ref. & lattice $(a, b, c)[\AA]$ & $\beta\left[^{\circ}\right]$ & $\mathrm{m}_{B}\left[\mu_{B}\right]$ & $\begin{array}{l}\text { Band } \quad \text { Gap } \\
{[\mathrm{eV}]}\end{array}$ & $\mathrm{XC}$ \\
\hline Peng 90 & $4.05,4.06,5.06$ & 90.02 & 0.0 & 0.0 & LSDA \\
\hline Peng 90 & $4.56,3.27,4.96$ & 100.2 & 0.63 & 1.32 & $\mathrm{LSDA}+\mathrm{U}(\mathrm{U}=7.5, \mathrm{~J}=0)$ \\
\hline Anisimov 98 & - & - & 0.66 & 1.9 & $\mathrm{LSDA}+\mathrm{U}(\mathrm{U}=7.5, \mathrm{~J}=0.98)$ \\
\hline Debbichi ${ }^{91}$ & $4.548,3.305,4.903$ & 99.652 & - & - & $\mathrm{LSDA}+\mathrm{U}(\mathrm{U}=7.5, \mathrm{~J}=0.98)$ \\
\hline Ekuma & $4.68,3.42,5.13$ & 90 & 0.68 & 1.25 & $\mathrm{DFT}+\mathrm{U}(\mathrm{U}=7.14)$ \\
\hline Heinemann 60 & $4.588,3.354,5.035$ & 99.39 & 0.66 & 1.39 & $\mathrm{LDA}+\mathrm{U}(\mathrm{U}=7.5, \mathrm{~J}=0.98)$ \\
\hline $\mathrm{Wu}^{93}$ & $4.55,3.34,4.99$ & 99.507 & 0.6 & 1.0 & $\mathrm{LSDA}+\mathrm{U}(\mathrm{U}=7.5, \mathrm{~J}=0.98)$ \\
\hline $\mathrm{Hu}^{92}$ & - & - & 0.63 & 1.1 & $\mathrm{GGA}+\mathrm{S}+\mathrm{U}(\mathrm{U}=7.5, \mathrm{~J}=0.98)$ \\
\hline Jiang 100 & $4.68,3.42,5.13$ & 99.54 & 0.80 & - & $\mathrm{GGA}+\mathrm{U}(\mathrm{U}=4.5)$ \\
\hline Nolan 101 & $4.395,3.846,5.176$ & - & $0.53-0.7$ & $0.17-2.11$ & $\mathrm{GGA}+\mathrm{S}+\mathrm{U}(\mathrm{U}=3-9, \mathrm{~J}=0)$ \\
\hline Svane 102 & - & - & 0.65 & 1.43 & SIC-LSDA \\
\hline Szotek $^{103}$ & - & - & 0.64 & 1.0 & SIC-LSDA \\
\hline Heinemann 60 & $4.513,3.612,5.141$ & 97.06 & 0.54 & 2.74 & HSE06 \\
\hline Lany $\underline{68}$ & - & - & - & 1.19 & $\mathrm{GW}+\mathrm{V}_{d}$ \\
\hline Exp. & $4.684,3.423,5.129^{81}$ & $99.54^{81}$ & 0.68 & $\begin{array}{l}1.2- \\
1.9^{10|41| 84|85| 104}\end{array}$ & - \\
\hline
\end{tabular}

Table 2: Calculations of the $\mathrm{CuO}$ bulk structure (lattice parameters $a, b, c$ in $\AA$, angle $\beta$ (between the $a$ and $c$ axes) in degrees, magnetic moment $m_{B}$ in Bohr magnetons and bang gap in $\mathrm{eV}$. The $\mathrm{S}$ in the functional name indicates spin-polarised calculations. All calculations featuring the Hubbard $U(+U$ in the functional name) have been done with the so-called 'Dudarev approach' ${ }^{\text {105 }}$, which requires two parameters, $\mathrm{U}$ and $\mathrm{J}$. $\mathrm{U}$ and $\mathrm{J}$ are in $\mathrm{eV}$.

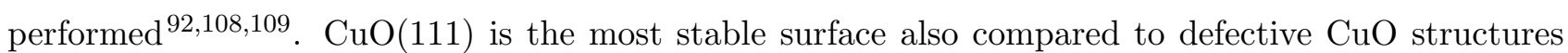
with surface and subsurface vacancies ${ }^{108}$, with surface energy $\gamma=0.74 \mathrm{~J} / \mathrm{m}^{2}$ (although much higher than the lowest energy $\mathrm{Cu}_{2} \mathrm{O}$ surface ${ }^{77}$ ). This is true for all oxygen partial pressures, except for a narrow range at very low $\mathrm{O}_{2}$ pressures, where the $\mathrm{Cu}$-terminated $\mathrm{CuO}(110)$ surface is favourable. The energy order of the stoichiometric surfaces is $(111)<(\overline{111})<(011)<(101)<(110)<(010)<(100)$ (shown in Fig. 3) 32 . The highest surface energies $\left(2.28 \mathrm{~J} / \mathrm{m}^{2}\right.$ for $\left.\mathrm{CuO}(100)\right)$ are associated to large fields between anionic and cationic layers, such as for the (010) and (100) surfaces. Among the nonstoichiometric surfaces, the O- and $\mathrm{Cu}$-terminated $\mathrm{CuO}(110)$ and $\mathrm{CuO}(100)$ are more stable than their stoichiometric counterpart for high (O-terminated) and low (Cu-terminated) oxygen pressures ${ }^{92}$.

While important information on stoichiometric and defective $\mathrm{CuO}$ surfaces has been obtained using computational methods, experimental data are lacking and there is room for work to be performed in order to either confirm these predictions or to suggest more possible structures.

\section{Initial stages of oxidation: oxygen adsorption on clean copper surfaces}

The growth of an oxide can occur when a metal surface comes into contact with an oxygen-rich environment. The reaction sequence leading to oxidation of a clean metal surface is generally accepted to be oxygen chemisorption, nucleation and growth of the surface oxide, and bulk oxide growth.

It is well known that clean copper surfaces in vacuum do not reconstruct 112 . However, exposure to oxygen pressure which is low enough not to trigger the formation of oxide-like structures induces reconstructions. We will discuss the details of these reconstructions below, and whether they are 


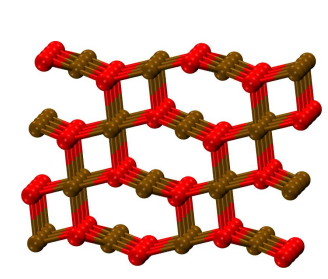

(111)

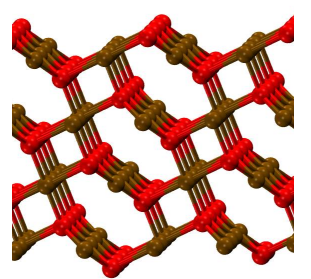

(111)

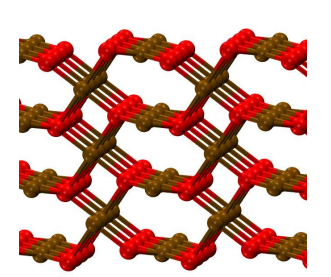

(110)

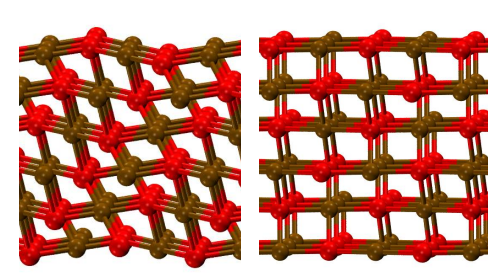

(011)
$(101)$

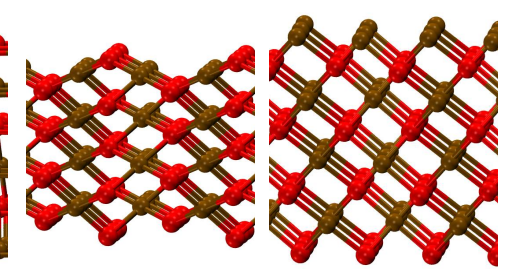

(010)

(100)

Figure 3: Side views of $\mathrm{CuO}$ slabs showing the structure of stoichiometric cupric oxide $\mathrm{CuO}$ surfaces. They are shown in order of increasing surface energy (left to right, top to bottom), as calculated using $a b$ initio calculations, using the GGA+U method ${ }^{92}$. Copper is shown in brown, oxygen in red.

a)
$\mathrm{Cu}(100)$

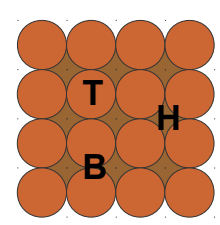

d)

$\mathrm{Cu}(110)$

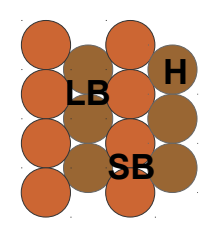

f)

$\mathrm{Cu}(111)$

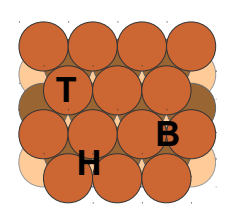

b)

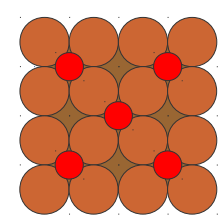

e)

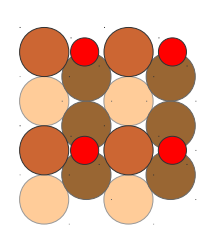

c)

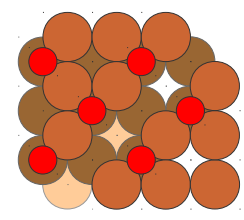

0 1st layer

0 2nd layer

- O 3rd layer

Cu 1st layer

Cu 2nd layer

Cu 3rd layer

g)

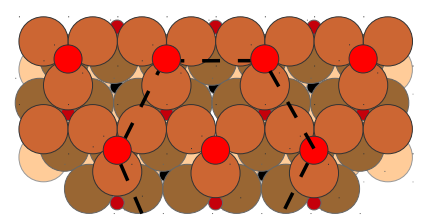

Figure 4: Overview of the structures formed by oxygen on different copper surfaces, at low oxygen exposures. a, d, f) Clean surfaces of $\mathrm{Cu}(100), \mathrm{Cu}(110)$ and $\mathrm{Cu}(111)$. T, H, B, SB and LB indicate respectively the top, hollow, bridge, short bridge and long bridge sites for adsorption. b) $c(2 \times 2)$ overlayer structure seen on $\mathrm{Cu}(100)$ at coverages $<0.3 \mathrm{ML}$. c) $(2 \sqrt{2} \times \sqrt{2}) R 45^{\circ}$ missing-row reconstruction seen on $\mathrm{Cu}(100)$ at coverages $>0.5 \mathrm{ML}$. e) $(2 \times 1)$ added-row reconstruction observed on the $\mathrm{Cu}(110)$ surface. g) $\mathrm{Cu}_{2} \mathrm{O}(111)$-like reconstruction of the $\mathrm{Cu}(111)$ surface having hexagonal geometry as shown by the dotted line. Two layers of subsurface oxygens are shown. Distorted variations of this reconstruction has been observed experimentally $110[111$. 
important to the initial stages of oxidation is still openly debated. It has been speculated that a reconstructed, O-saturated layer must form before the onset of oxidation, since dwell times, i.e. the lapse of time between the beginning of oxygen deposition and observation of oxide formation, of up to 30 minutes have been observed ${ }^{113}$ 115. Moreover, evidence of the existence of the reconstructed copper surfaces and of subsurface growth of the oxide before the onset of island formation, has been produced using $\mathrm{STM}$ on $\mathrm{Cu}(100)^{\frac{116}{16}}$ and $\mathrm{Cu}(111)^{117}$. DFT calculations have shown that, on $\mathrm{Cu}(100)$, subsurface oxide-like structures are more easily produced when the surface already has pre-adsorbed oxygen atoms, thus suggesting that the reconstruction facilitates oxide formation 118 . However, it

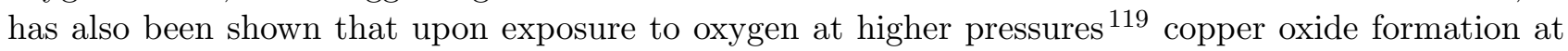
step sites occurs without prior surface reconstruction thus opening the debate about whether direct formation of oxide islands can occur without the formation of a $\mathrm{O} / \mathrm{Cu}$ overlayer.

In the following section, the very initial stage of the oxidation process, i.e. the chemisorption of oxygen onto copper surfaces is reviewed. A summary of the overlayer structures formed on $\mathrm{Cu}$ after O-dosing is shown in Fig. 4. $\mathrm{Cu}(100)$ presents two main reconstructions, one with $c(2 \times 2)$ symmetry (Fig. 4b) and a missing-row reconstruction (Fig. 4,), which are discussed in depth in Sec. 4.1. The main overlayer structure for $\mathrm{Cu}(110)$ is the added-row reconstruction shown in Fig. 4p and discussed in Sec. 4.2), while the $\mathrm{O} / \mathrm{Cu}(111)$ system, presented in Sec. 4.3 shows a distorted hexagonal structure resembling the $\mathrm{Cu}_{2} \mathrm{O}(111)$ surface (Fig. $4 \mathrm{~g}$ ).

Oxygen adsorption on clean copper has been extensively studied experimentally and computationally, and it has been the subject of a number of reviews over the years, e.g. see Refs. 1201121 . Here we focus only on the studies which are relevant in order to understand the onset of copper oxidation on the $\mathrm{Cu}(100),(110)$ and (111) surfaces and on the most recent developments in the field.

\section{$4.1 \mathrm{Cu}(100)$}

Oxygen adsorption on $\mathrm{Cu}(100)$ has been widely studied $116|121| 122$, and an interesting variety of structures is formed depending on temperature and coverage, as shown in the phase diagram in Fig. $5 \mathrm{a}$.

At low temperatures (up to $100 \mathrm{~K}$ ) and low coverage ( $\sim 0.1$ monolayers, ML, defined as one adsorbed oxygen atom for every surface copper atom) experimental and computational evidence has shown that incident oxygen molecules dissociate with the oxygen atoms adsorbing at the hollow site 123 . These dissociated oxygen atoms stabilize chemisorption of further incoming oxygen molecules at higher coverages 129 132.

Below $473 \mathrm{~K}$, two overlayer structures form: a $c(2 \times 2)$ phase 116$] 133-136$ at a coverage of $\sim 0.3 \mathrm{ML}$ and a $(2 \sqrt{2} \times \sqrt{2}) R 45^{\circ}$ missing-row $(\mathrm{MR})$ reconstruction 137146 at $\sim 0.5 \mathrm{ML}$. In the $c(2 \times 2)$ phase (shown in Fig. 4b) the oxygen atoms occupy four-fold hollow sites on $\mathrm{Cu}(100)$ and form nanometre-sized $c(2 \times 2)$ domains separated by oxygen-deficient zig-zag shaped boundaries. The MR reconstruction (Fig. 4c, 5b) can be viewed as a $c(2 \times 2)$ structure with each fourth [100] row of Cu atoms missing. Between 0.3 and $0.5 \mathrm{ML}, \mathrm{Cu}$ atoms are ejected from the $c(2 \times 2)$ domains $\frac{118 \mid 147}{1}$ and MR islands start forming on terraces, until, at 0.5 ML coverage, a network of missing-row reconstruction islands covers the whole surface ${ }^{116[133}$.

At high temperatures $(473<\mathrm{T}<1000 \mathrm{~K})$ a $c(2 \times 2)$-like state, with $25 \%$ vacancies in the top $\mathrm{Cu}$ layer forms at $0.5 \mathrm{ML}$ coverage, instead of the MR reconstruction 148 .

No further oxygen adsorption occurs above $0.5 \mathrm{ML}$ for experiments at very low pressures $\left(<\sim 10^{-7}\right.$ Torr). However, at higher pressures, further exposure of the surface to $\mathrm{O}_{2}$ leads to growth of oxide in the subsurface regions, while the surface still exhibits the MR reconstruction ${ }^{[16 \mid 141]}$, validating the hypothesis that oxygen-induced surface reconstruction is indeed the first step of oxide growth.

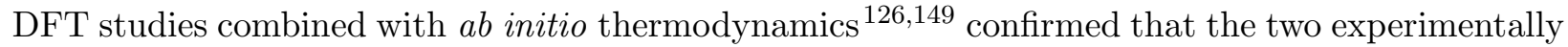
observed reconstructions at lower temperatures are the most stable during the early stages of $\mathrm{Cu}(100)$ oxidation prior to the onset of bulk oxidation. 

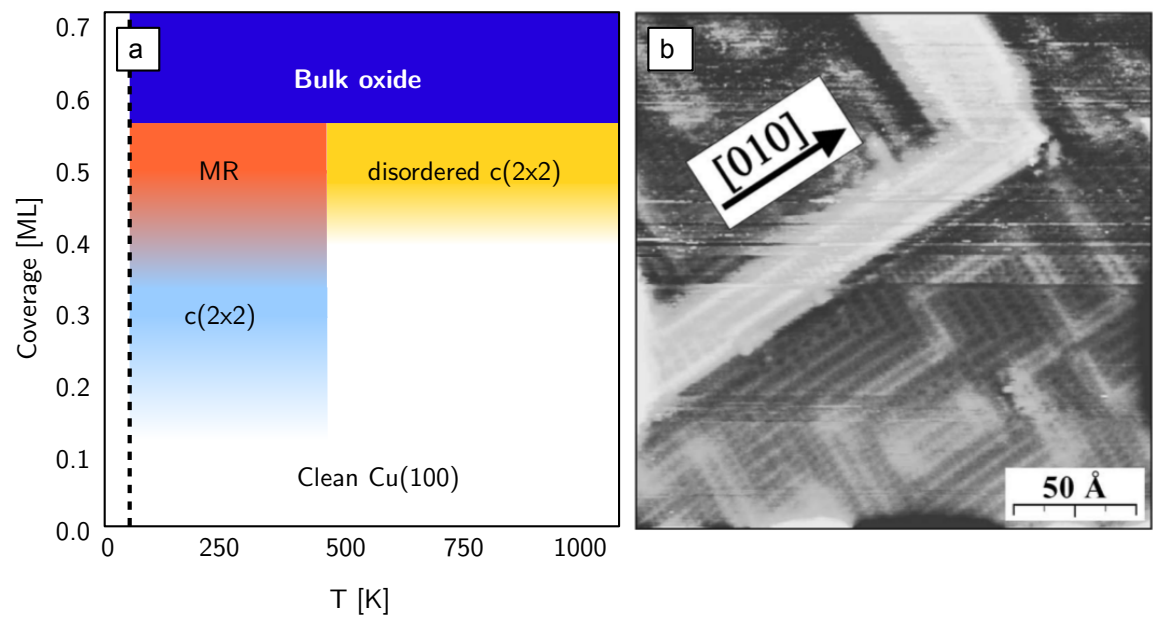

Figure 5: a) Summary of the structures forming on $\mathrm{Cu}(100)$ after oxygen exposure. The dashed line indicates the lowest temperature at which experiments have been performed $(30 \mathrm{~K})$ for this system. The areas in white represent domains where no ordered oxygen overlayers form. For low temperatures, at coverages of $\sim 0.3 \mathrm{ML}$ the $c(2 \times 2)$ structure forms and at $\sim 0.5 \mathrm{ML}$ the missing row $(\mathrm{MR})$ reconstruction is seen. At intermediate coverages both structures exist. At high temperatures a 'disordered' $c(2 \times 2)$ structure occurs. At coverages over 0.5 ML subsurface oxide starts to grow. b) STM image of $\mathrm{Cu}(100)$ after $\mathrm{O}_{2}$ exposure $\left(P=3.7 \times 10^{-2} \mathrm{mbar}, T=373 \mathrm{~K}\right) . \mathrm{A}(2 \sqrt{2} \times \sqrt{2}) R 45^{\circ}$ island and a zigzag phase boundary (bright stripe) are visible. The missing rows of $\mathrm{Cu}$ run along the $\langle 001\rangle$ directions and are imaged as depressions. Taken from Ref.116.

The transition between the two low-temperature reconstructions has been tentatively explained in terms of stress relief, electrostatics and orbital hybridization. Compressive surface stress has been shown, both by means of experiments and DFT calculations $\frac{150 \mid 151}{10}$ increase with oxygen adsorption, and to be higher in the $c(2 \times 2)$ reconstruction. Therefore the MR reconstruction is more stable at higher oxygen coverages. Electrostatically, the driving mechanism for oxygen overlayer formation has been related to long-range Coulomb interaction $\frac{152}{157}$, and the small size of the $c(2 \times 2)$ domains to repulsion between $\mathrm{O}$ adatoms and $\mathrm{Cu}$ and $\mathrm{O}$ adatoms. At coverages where the $\mathrm{O}$ atoms have nowhere to form distinct $c(2 \times 2)$ domains the phase transition occurs to minimize high O-O repulsion. This is in disagreement with the findings of Merrick et al. $\stackrel{158}{ }$, who argue that the stability of the MR system is determined by orbital hybridization of neighbouring $\mathrm{O}-\mathrm{Cu}$ which lowers the energy of the system, rather than by long-range interactions.

The transition between the ordered MR to the 'disordered' $c(2 \times 2)$ reconstruction has been explained by means of DFT in terms of diffusion of $\mathrm{Cu}$ surface vacancies from an ordered array in the MR system to random positions as the temperature increases $\underline{148}$.

An intermediate added row structure was predicted by Kangas et al. ${ }^{159}$ which has energies comparable to the MR reconstruction. This reconstruction has however not yet been observed experimentally, possibly because the right conditions of temperature and pressure for this structure have not been used ${ }^{116}$. Ab initio thermodynamics calculations could approximately establish at which experimental conditions this reconstruction is expected and could thus inform further experimental work.

It is important to note that simulations have shown that the MR structure is a necessary step towards the formation of a $\mathrm{Cu}_{2} \mathrm{O}$-like structure ${ }^{118 \mid 160}$. Indeed, $\mathrm{Cu}_{2} \mathrm{O}$-like structures were found to form on the $\mathrm{MR}$ reconstruction upon $\mathrm{O}$ adsorption which were not found on the non-reconstructed surface, thus confirming the experimental results of Lahtonen et al. $\frac{116}{16}$ and fitting well with the work of Zhou et al. $\stackrel{161}{16}$, who finds the presence of a two-layer thick oxide before the formation of oxide islands of the $\mathrm{Cu}(100)$ surface (see Sec. 5.1). 
In summary, three reconstructions can form on $\mathrm{Cu}(100)$ upon oxygen adsorption, as shown in Fig. 5. Of these, the MR reconstruction is the most stable at room temperature, for coverages $\sim 0.5$ ML. Experimental and computational evidence has shown that the formation of this reconstruction is the first step towards the formation of the bulk oxide.

\section{$4.2 \mathrm{Cu}(110)$}

Molecular oxygen dissociates when deposited on $\mathrm{Cu}(110)$ at temperatures above $45 \mathrm{~K}^{162}$. Upon dissociation of the $\mathrm{O}_{2}$ molecules a number of overlayer structures are observed, including an added-row $(2 \times 1)$ structure (Fig. 4 4 ) which is formed at an oxygen coverage of $0.5 \mathrm{ML}$ 121/145/163 165. Another type of surface reconstruction, $c(6 \times 2)$, has also been reported at high coverage $(\sim 2 / 3 \mathrm{ML}) \underline{145 \mid 165} 1172$ or at lower coverage but higher temperature ${ }^{173}$.

The $(2 \times 1)$ phase forms via the creation of $\mathrm{Cu}-\mathrm{O}-\mathrm{Cu}-\mathrm{O}$ chains along the [001] direction of the substrate, which eventually become the 'added rows' on top of the clean substrate at a coverage of $0.5 \mathrm{ML}$. The chains start forming above $70 \mathrm{~K}$ but do not fully organize until $\sim 200 \mathrm{~K}^{162}$. They are formed from mobile chemisorbed $\mathrm{O}$ atoms and $\mathrm{Cu}$ adatoms which leave from step edges and diffuse across the terraces $138|162| 174$ 178. The experimental barrier calculated for the formation of these strings, $0.22 \pm 0.01 \mathrm{eV}^{179}$, is close to the DFT-calculated barriers for $\mathrm{Cu}(0.25 \mathrm{eV})$ and $\mathrm{O}(0.15 \mathrm{eV})$ diffusion 180 .

At oxygen coverages between 0.05 and $0.45 \mathrm{ML}$ these $\mathrm{Cu}-\mathrm{O}-\mathrm{Cu}-\mathrm{O}$ chains self-organize in a periodic array (called a supergrating) with a spacing varying between 60 and $140 \AA^{138 \mid 181+184}$. The dependence of the period of the supergrating as a function of oxygen coverage has been explained in terms of electrostatic $^{185}$ and elastic interactions ${ }^{186}[191$. In the first case, the period has been related to the difference in work function between the clean and reconstructed sections of the surface, in the second case to stress relief from the mismatch between the preferred period of the $\mathrm{Cu}-\mathrm{O}-\mathrm{Cu}-\mathrm{O}$ chains and the period of the $\mathrm{Cu}(110)$ substrate in the [001] direction. It could indeed be possible for both mechanisms to be at play.

The stability of the $(2 \times 1)$ reconstruction at $0.5 \mathrm{ML}$ has been established computationally by means of semiempirical and DFT calculations, where it has been found to be energetically favourable with respect to the unreconstructed surface ${ }^{179|180| 192 \mid 193}$ and to an alternative added row $(4 \times 1)$ geometry ${ }^{190}$. DFT simulations with ab initio thermodynamics ${ }^{126|172| 194}$ found that the $\mathrm{Cu}-\mathrm{O}$ added row reconstruction is favoured at low oxygen exposures, whereas at higher oxygen exposures, a transition to the $c(6 \times 2)$ structure is predicted to occur. Thus, experiment and theory are in qualitative agreement, although the absolute transition pressures vary enormously (by 10 orders of magnitude). Since it is a major challenge for current DFT XC functionals to accurately predict adsorption energies and the underlying value of the adsorption energy has a huge impact on subsequence pressure estimates, such a quantitive discrepancy is not uncommon? ? ? The barrier to transition between the two structures has been calculated to be fairly high at $1.41 \mathrm{eV}$, which seems to explain why this phase is observed only at high temperatures.

A large amount of work has been performed in order to understand the surface electronic states of the added row reconstruction, using both experimental methods such as photoemission spectroscopy 195 and theory 208200 . The character of the $\mathrm{O}-\mathrm{Cu}$ bonding is found to be predominantly ionic, and the surface $\mathrm{O}(2 p)$ orbitals hybridize strongly with the $\mathrm{Cu}(3 d)$ states, forming bonding and antibonding linear combinations, with the antibonding bands not having been identified unambiguously yet.

There is no evidence so far on how the observed reconstruction relates to the initial formation of the oxide, if at all. DFT calculations of subsurface oxygen added beneath both reconstructed surfaces have found that when an $\mathrm{O}$ coverage of $1 \mathrm{ML}$ is reached, subsurface oxide formation in the tetrahedral interstitial sites is predicted to occur 201 . The presence of oxygen in the tetrahedral site has been linked to oxide formation (since the $\mathrm{O}$ in $\mathrm{Cu}_{2} \mathrm{O}$ resides in the tetrahedral sites), and therefore this is a possible mechanism for the initial formation of the oxide, which should however be confirmed by experimental 
or further computational work.

\section{$4.3 \mathrm{Cu}(111)$}

The clean (111) surface has the lowest surface energy for copper and it is less reactive compared to the other low-index $\mathrm{Cu}$ surfaces. It is therefore less studied for oxygen adsorption $110|111| 114|129| 130|202| 210$. No ordered structures are observed experimentally for low oxygen exposure 114 |204|205|211. Indeed, also DFT studies have found that oxygen adsorbs preferentially at the threefold hollow site for coverages up to $0.75 \mathrm{ML}$, without forming periodic overlayer structures $\underline{49212} 214$.

At higher coverage, the adsorbed oxygen and copper adatoms that are ejected from step edges and terraces $117 / 209 / 210$ start forming overlayer structures, before the onset of epitaxial growth (see Sec. 5.3). Two main classes of reconstructions have been proposed for the $\mathrm{O} / \mathrm{Cu}(111)$ surface. The first, seen in LEED studies, involves a $\mathrm{Cu}(100)$-like overlayer, incommensurate with the underlying unreconstructed $\mathrm{Cu}(111)$ surface, with the oxygen atoms occupying the hollow sites $215 \mid 216$. The second

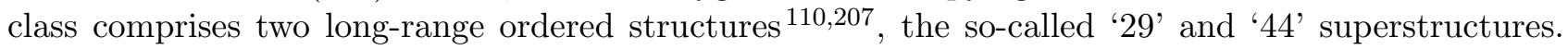
They have, respectively, $\left(\sqrt{13} R\left(46.1^{\circ} \times 7 R 21.8^{\circ}\right)\right.$ and $\left(\sqrt{73} R 5.8^{\circ} \times \sqrt{21} R-10.9^{\circ}\right)$ symmetry and very large surface unit cells, 29 and 44 times larger than the $1 \times 1$ cell of clean $\mathrm{Cu}(111)$. They exhibit an honeycomb pattern formed by distorted honeycomb units of the 'ideal' $\mathrm{Cu}_{2} \mathrm{O}(111)$ overlayer shown in Fig. $4 \mathrm{~g}$. The oxide-like overlayer structure has been confirmed by STM ${ }^{209}$, X-ray absorption studies 111 and DFT and $a b$ initio molecular dynamics ${ }^{49 / 78}$. This differs from the behaviour of other $\mathrm{O} /$ transition metal systems such as $\mathrm{O} / \mathrm{Ag}(111)^{217 / 218}$ and $\mathrm{O} / \mathrm{Pd}(111)^{219}$, where chemisorbed oxygen adlayers form, before the formation of a surface oxide. Other systems, such as $\mathrm{O} / \mathrm{Ru}(0001)^{220}$ and $\mathrm{O} / \mathrm{Rh}(111)^{221 \mid 222}$, instead never form a surface oxide layer before the onset of bulk oxidation.

Therefore, both experimental and computational studies point to the formation of hexagonal or quasi-hexagonal structures on the $\mathrm{Cu}(111)$ surface upon oxygen adsorption, structures which can be viewed as the initial layer of a $\mathrm{Cu}_{2} \mathrm{O}(111)$ film and which can potentially act as a template for the growth of further $\mathrm{Cu}_{2} \mathrm{O}(111)$ layers.

\section{Oxide film growth}

When copper surfaces are exposed to a continuous flow of oxygen for a long time oxidation is expected to occur. It is known in general, from well-defined surface science studies of metals, such as those discussed in Sec. 4, that the $\mathrm{O} /$ metal structure which forms at the onset of oxidation can be distinct from the bulk oxide surface structure $14|223| 224$. The growth of oxides in copper has been studied since the early 1920s and early work has been extensively reviewed (see e.g. Ref. ${ }^{(14}$ ). In this section, we aim to present an overview of the main topics in the field of copper oxide growth mainly focusing on recent studies and on the present state of experiments and theory.

In order to understand the microscopic details of the onset of oxidation, experiments have been performed in controlled laboratory conditions, where the orientation of the surface, temperature and oxygen pressures can be tuned to the required values. The formation of the oxide has been directly observed by means of TEM, and their structure analysed by means of LEED and ellipsometry. At the oxygen pressure, temperature and exposure times used in these studies, only cuprous oxide is expected to form $\frac{391225 \mid 226}{3}$. We review studies showing that the growth of cuprous oxide on low-index copper surfaces is epitaxial with the substrate $\sqrt{14 \mid 227}[230$, through nucleation and coalescence of nano-

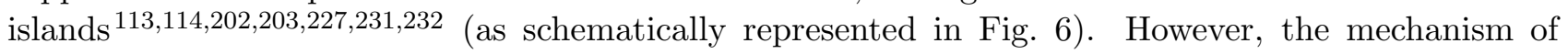
formation of the islands and the resulting shapes and growth rates are strongly dependent on the $\mathrm{Cu}$ substrate, as shown in Sec. 5.1 for $\mathrm{Cu}(100)$, Sec. 5.2 for $\mathrm{Cu}(110)$ and Sec. 5.3 for $\mathrm{Cu}(111)$. Key experimental findings are summarised in Tables 3, 4, 5. The kinetic models for the nucleation and 

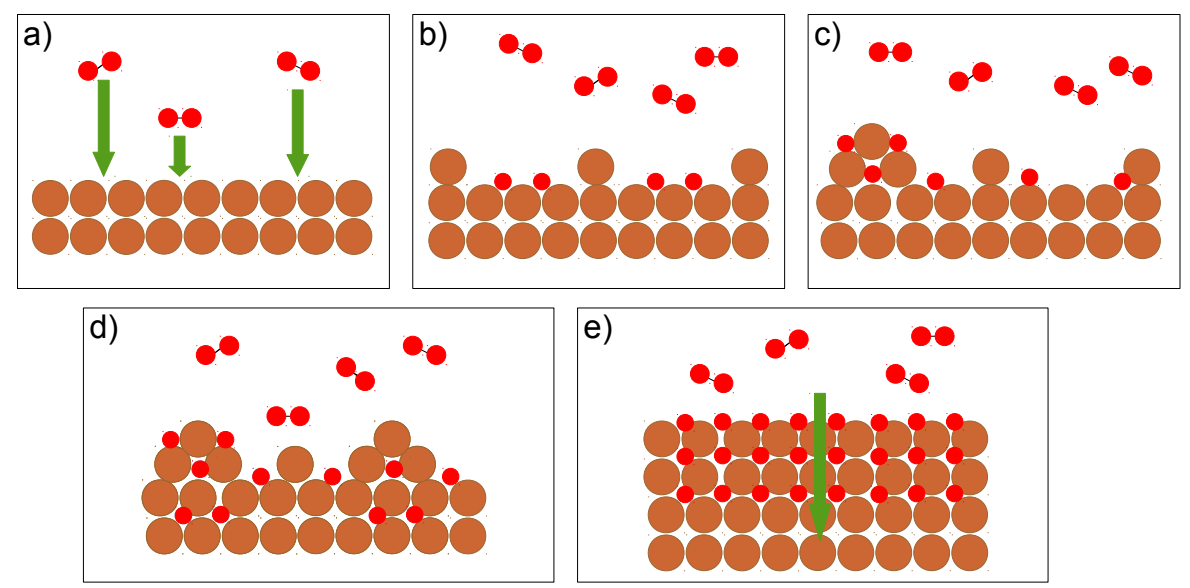

Figure 6: Schematic illustration of the stages of growth of a copper oxide film on copper. a) Gas-phase oxygen molecules and clean copper surface. b) Upon adsorption of the oxygen, the copper surface reconstructs. c) Nucleation of oxide islands upon diffusion of oxygen on the reconstructed surface, until the island saturation density $\left(N_{\text {sat }}\right)$ is reached. d) Growth of the oxide islands. As the islands grow bigger direct oxygen impingement on the islands starts playing a more important role. e) After the islands coalesce oxide growth proceeds through interfacial diffusion of oxygen.

coalescence of the nano-islands and for the growth of the oxide thin film are reviewed in Sec. 5.4 and Sec. 5.5 .

Growth of the oxide in ambient conditions, when the copper surface is exposed to humid air, has also been extensively studied. The body of work addressing this issue is reviewed in Sec. 5.5 and summarised in Table 6 .

Finally, the existence of preferential oxidation sites is discussed (Sec. 5.7) and studies on the initial growth of $\mathrm{CuO}$ are reviewed (Sec. 5.8).

\subsection{Oxide nano-islands: $\mathrm{Cu}(100)$}

As for the formation of $\mathrm{O} / \mathrm{Cu}$ overlayers, $\mathrm{Cu}(100)$ is the most extensively studied surface, both experimentally and computationally. Copper oxidation on this surface proceeds, for low oxygen partial pressures $\left(P \sim 10^{-4}\right.$ Torr $)$, through the formation of islands which are epitaxial with the surface, i.e. $\mathrm{Cu}_{2} \mathrm{O}(100) \| \mathrm{Cu}(100)^{113|115| 231|233| 236}$ and have $6 \times 7$ lattice misfit configuration ${ }^{225 \mid 237}$. These islands grow and coalesce with further oxygen deposition. The shape of the islands depends on temperature $\mathrm{e}^{238}$ in a rather interesting manner as shown in Fig. 7. Below $350{ }^{\circ} \mathrm{C}$ only triangular islands are observed, whereas between $400-550{ }^{\circ} \mathrm{C}$ the shape changes to round or square. At around $600{ }^{\circ} \mathrm{C}$ the islands start to grow until, at a critical size of $\sim 110 \mathrm{~nm}$, when they switch to a quasi-one-dimensional elongated rod shape. Between $650-800{ }^{\circ} \mathrm{C}$ pyramid-shaped islands are observed and between $800-1000{ }^{\circ} \mathrm{C}$ hollow pyramids form 239 . The big effect of temperature on the morphology of the islands could be either due to the dependence of copper and oxygen diffusion on temperature or to changes in interfacial strains and in the mechanical properties. Indeed, the transition between the round/square to rod shape shown in Fig. 7b,c has been explained as a competition between the surface energy and the strain of the islands due to the mismatch between the clean metal and the oxide lattices, following the so-called Tersoff-Tromp 240 energy model.

TEM, XPS and AES studies looking at the cross section of an oxidising $\mathrm{Cu}(100)$ single crystal under low oxygen partial pressure $\mathrm{e}^{115|161| 241 \mid 242}$ have revealed that the oxide islands form on top of an oxide wetting layer. The wetting layer itself has a $(\sqrt{2} \times 2 \sqrt{2}) R 45^{\circ}$ missing row reconstruction and forms 

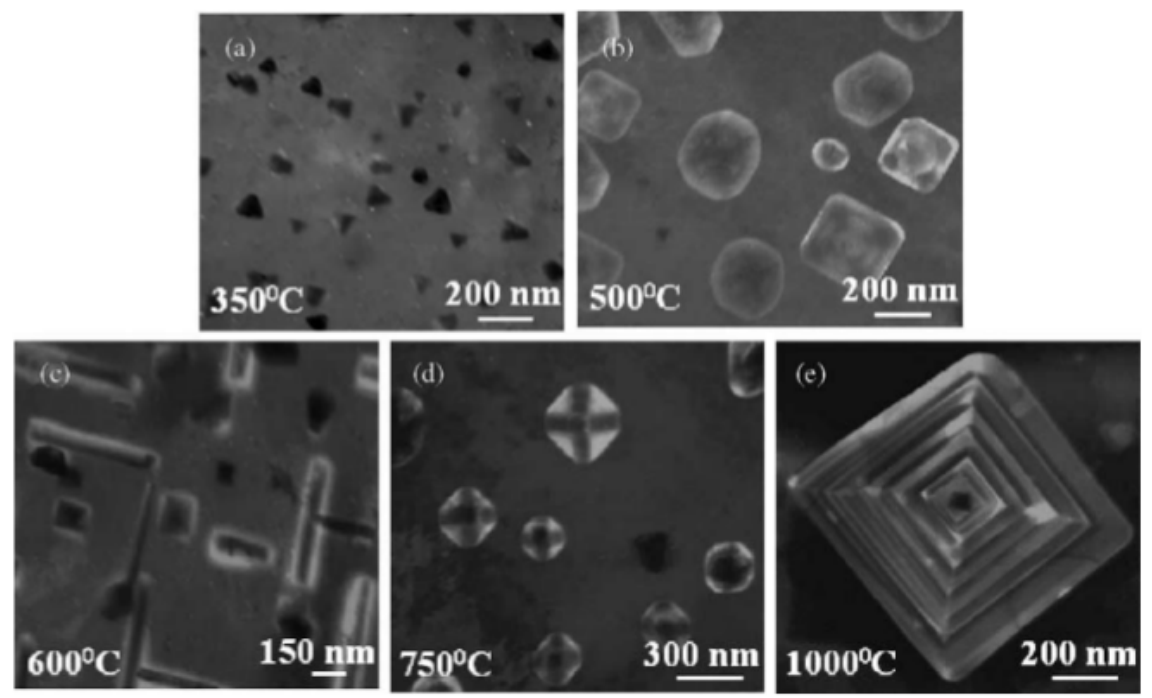

Figure 7: Oxide islands observed on the $\mathrm{Cu}(100)$ surface using in situ TEM imaging, for a set of temperatures between $350-1000{ }^{\circ} \mathrm{C}$. The oxidation partial pressure is $P=5 \times 10^{-4}$ Tor. A large variety of island structures are observed, according to the oxidation temperature. Taken from Ref. $\frac{238}{\text {. }}$

from the $\mathrm{Cu}$ atoms ejected by the missing row reconstruction of the substrate (described in Sec. 4.1) and the further oxygen deposited on the substrate 241 . Island growth also occurs beneath the surface, in good agreement with the already reviewed results by Lahtonen et al. $\frac{116}{\text { (Sec. } 4.1)}$ who observed subsurface oxide growth for oxygen coverages above $0.5 \mathrm{ML}$ and pressures above $\sim 10^{-7}$ Torr.

In general, when a metal is capable of forming uniform subsurface oxides (as in the case of $\operatorname{Ag}(110)^{243}$ and $\left.\mathrm{Ru}(0001)^{\underline{244}}\right)$, oxide growth proceeds uniformly, rather than via island formation. The reason for the island formation on top of the wetting layer is found in stress mismatch between the $\mathrm{Cu}(100)$ substrate and the $\mathrm{Cu}_{2} \mathrm{O}(100)$ film 161 .

The transition between the $\mathrm{O} / \mathrm{Cu}(100)$ system described in Sec. 4.1 and the oxide islands has been studied to some extent with DFT, and although the full transition has not been modelled yet, insight has been gained into the mechanisms at play. On the MR reconstructed surface, sub-surface adsorption becomes favourable for $\mathrm{O}$ coverage above 1.0 ML, with low barriers for the transport of oxygen atoms below the surface 245 247. Sub-surface oxygen atoms below the missing-row reconstruction adsorb in the tetrahedral interstitial sites, and thus form an oxide-like structure, unlike the case of sub-surface oxygen atoms below non-reconstructed surfaces, which adsorbs in the octahedral site ${ }^{160}$. However, the limiting factor for the oxidation of $\mathrm{Cu}(100)$ is the dissociation and on-surface diffusion of the oxygen molecule. The dissociation of the oxygen molecule, although almost barrierless on the clean $\mathrm{Cu}(100)^{124}$, is blocked by the on-surface oxygen on the reconstructed surface $\mathrm{e}^{248}$, and requires the diffusion of the oxygen molecule towards either a high- $\mathrm{Cu}$ concentration area ${ }^{153}$ or vacancies and surface defects ${ }^{249 \mid 250}$ where the dissociation barrier is lower. Diffusion of $\mathrm{O}$ and $\mathrm{Cu}$ atoms on the $\mathrm{MR}$ reconstructed surface is slow, having barriers of $1.4 \mathrm{eV}$ for oxygen and $2.0 \mathrm{eV}$ for $\mathrm{Cu}^{153}$. The high barriers and slow diffusion make these processes difficult to simulate. Indeed, Devine et al. 251 successfully simulated oxygen molecule dissociation on the clean $\mathrm{Cu}(100)$ surface with bond-order potentials, however they did not see any dissociation event on the missing-row reconstructed surface within their (short) $10 \mathrm{ps}$ of molecular dynamics. This highlights the difficulty of reproducing these complex phenomena which include diffusion of oxygen molecules, dissociation, diffusion of oxygen and copper atoms on and through the surface using standard computational approaches. To this end, the combination of an accurate reactive potential with methods which allow for rare events to be probed, 
such as metadynamics 252 are possibly a way to go for this type of system.

\begin{tabular}{|c|c|c|c|c|c|}
\hline Reference & $\begin{array}{l}\text { Sample } \\
\text { thickness }\end{array}$ & Surface Preparation & $\begin{array}{l}\text { Exp. Condi- } \\
\text { tions }\end{array}$ & Technique & Result \\
\hline $\begin{array}{l}\text { Brockway } 231- \\
(1972)\end{array}$ & $90 \mathrm{~nm}$ & $\begin{array}{l}\text { Annealing in } \mathrm{H}_{2} \text { at } \mathrm{T}=630 \\
{ }^{\circ} \mathrm{C}\end{array}$ & $\begin{array}{ll}\mathrm{P}=10^{-3} & \text { Torr } \\
\mathrm{T}=525^{\circ} \mathrm{C} & \end{array}$ & TEM & $\begin{array}{l}\text { Epitaxial growth of ox- } \\
\text { ide islands. }\end{array}$ \\
\hline $\begin{array}{l}\text { Heinemann } \\
(1975)\end{array}$ & $80 \mathrm{~nm}$ & $\begin{array}{l}\text { Annealing, argon ion sputter } \\
\text { etching }\end{array}$ & $\begin{array}{l}\mathrm{P}=5 \times 10^{-3} \text { Torr } \\
\mathrm{T}=425{ }^{\circ} \mathrm{C}\end{array}$ & TEM & $\begin{array}{l}\text { Epitaxial growth of } \\
\text { square and hexagonal } \\
\text { oxide islands. }\end{array}$ \\
\hline $\begin{array}{l}\text { Stefanov } \\
(1988)\end{array}$ & - & $\begin{array}{l}\text { Ion bombardment and heat- } \\
\text { ing under UHV }\end{array}$ & $\begin{array}{l}10 \text { to } 2 \times 10^{6} \mathrm{~L} \\
\mathrm{~T}=-130-180^{\circ} \mathrm{C}\end{array}$ & $\begin{array}{l}\text { HREELS, } \\
\text { XPS }\end{array}$ & $\begin{array}{l}\mathrm{Cu}_{2} \mathrm{O} \text { formation at oxy- } \\
\text { gen exposures between } \\
10^{5}-2 \times 10^{6} \mathrm{~L}\end{array}$ \\
\hline $\begin{array}{l}\text { Yang } 233 \\
(1997)\end{array}$ & $40 \mathrm{~nm}$ & $\begin{array}{l}\text { Annealing in methanol } \\
\text { vapour at } 350^{\circ} \mathrm{C}\end{array}$ & $1.5 \times 10^{-5}$ Torr & TEM & $\begin{array}{l}\text { Rate of growth of the ox- } \\
\text { ide islands } \propto t^{1.3} \text {. }\end{array}$ \\
\hline $\begin{array}{l}\text { Yang } 115 \\
(1998)\end{array}$ & $100 \mathrm{~nm}$ & $\begin{array}{l}\text { Annealing in } \mathrm{UHV} / \mathrm{CH}_{4} \mathrm{O} \\
\text { vapour at } 350{ }^{\circ} \mathrm{C}\end{array}$ & $\begin{array}{l}1 \times 10^{-5}-1 \times 10^{-4} \\
\text { Torr }\end{array}$ & TEM & $\begin{array}{l}\text { O monolayer forms be- } \\
\text { fore growth of the oxide } \\
\text { islands. }\end{array}$ \\
\hline $\begin{array}{l}\text { Yang } \\
(1998)\end{array}$ & $60 \mathrm{~nm}$ & $\begin{array}{l}\text { Annealing in methanol } \\
\text { vapour at } 350{ }^{\circ} \mathrm{C}, 5 \times 10^{-5} \\
\text { Torr }\end{array}$ & $\begin{array}{l}5 \times 10^{-5}-760 \text { Tor } \\
\text { at } 60-600{ }^{\circ} \mathrm{C}\end{array}$ & TEM & $\begin{array}{l}\text { Epitaxial island forma- } \\
\text { tion after surface recon- } \\
\text { struction. }\end{array}$ \\
\hline $\begin{array}{l}\text { Yang } 234 \\
(1998)\end{array}$ & $100 \mathrm{~nm}$ & $\begin{array}{l}\text { Annealing in } \mathrm{CH}_{4} \mathrm{O} \text { vapour } \\
\text { at } 350^{\circ} \mathrm{C}, 5 \times 10^{-5} \text { Torr }\end{array}$ & $\begin{array}{l}5 \times 10^{-4} \text { Tor } 290- \\
435{ }^{\circ} \mathrm{C}\end{array}$ & TEM & $\begin{array}{l}\text { Nucleation of islands } \\
\text { promoted by } \mathrm{O} \text { diffusion. }\end{array}$ \\
\hline $\begin{array}{l}\text { Yang } 254 \\
(1999)\end{array}$ & $100 \mathrm{~nm}$ & $\begin{array}{l}\text { Annealing in } \mathrm{CH}_{4} \mathrm{O} \text { vapour } \\
\text { at } 350^{\circ} \mathrm{C}, 5 \times 10^{-5} \text { Torr }\end{array}$ & $\begin{array}{l}1 \times 5^{-5}-5 \times 10^{-4} \\
\text { Tor } 70-600{ }^{\circ} \mathrm{C}\end{array}$ & TEM & $\begin{array}{l}\text { Preferential nucleation } \\
\text { site at the edge of holes. }\end{array}$ \\
\hline $\begin{array}{l}\text { Yang } \\
(2001)\end{array}$ & $\begin{array}{l}60-100 \\
\mathrm{~nm}\end{array}$ & $\begin{array}{l}\text { Annealing in } \mathrm{CH}_{4} \mathrm{O} \text { vapour } \\
\text { at } 350{ }^{\circ} \mathrm{C}, 5 \times 10^{-5} \text { Torr }\end{array}$ & $\begin{array}{l}\mathrm{O}_{2} / \mathrm{H}_{2} \mathrm{O} \text { vapour } \\
\text { at } 5 \times 10^{-4} \text { Tor at } \\
350{ }^{\circ} \mathrm{C}\end{array}$ & TEM & $\begin{array}{l}\text { Initial surface recon- } \\
\text { struction prior to island } \\
\text { growth. }\end{array}$ \\
\hline $\begin{array}{l}\text { Yang } 235 \\
(2002)\end{array}$ & $60 \mathrm{~nm}$ & $\begin{array}{l}\text { Annealing in } \mathrm{CH}_{4} \mathrm{O} \text { vapour } \\
\text { at } 350{ }^{\circ} \mathrm{C}, 5 \times 10^{-5} \text { Torr }\end{array}$ & $\begin{array}{l}5 \times 10^{-5}-760 \\
\text { Torr at } 60-600 \\
{ }^{\circ} \mathrm{C}\end{array}$ & TEM & $\begin{array}{l}\text { Good agreement of } \\
\text { kinetic data with the } \\
\text { JMAK model. }\end{array}$ \\
\hline $\begin{array}{l}\text { Zhou } \\
(2003)\end{array}$ & $70 \mathrm{~nm}$ & $\begin{array}{l}\text { Annealing in } \mathrm{CH}_{4} \mathrm{O} \text { vapour } \\
\text { at } 350{ }^{\circ} \mathrm{C}, 5 \times 10^{-5}\end{array}$ & $\begin{array}{l}5 \times 10^{-4} \text { Torr at } \\
150-1000{ }^{\circ} \mathrm{C}\end{array}$ & TEM & $\begin{array}{l}\text { Temperature-dependent } \\
\text { shape of oxide nano- } \\
\text { islands. }\end{array}$ \\
\hline $\begin{array}{l}\text { Eastman } \\
(2005)\end{array}$ & $\begin{array}{l}110-200 \\
\mathrm{~nm}\end{array}$ & $\begin{array}{l}\text { Annealing in } \mathrm{Ar}-2 \% \mathrm{H}_{2} \text { at } \\
850{ }^{\circ} \mathrm{C}, 5 \times 10^{-5} \text { Torr }\end{array}$ & $\begin{array}{l}5 \times 10^{-4} \text { Torr at } \\
350-780{ }^{\circ} \mathrm{C}\end{array}$ & $\begin{array}{l}\text { X-ray } \\
\text { scattering }\end{array}$ & $\begin{array}{l}\text { Epitaxial nano-island } \\
\text { formation. }\end{array}$ \\
\hline $\begin{array}{l}\text { Zhou } \\
(2005)\end{array}$ & $70-80 \mathrm{~nm}$ & $\begin{array}{l}\text { Annealing in } \mathrm{CH}_{4} \mathrm{O} \text { vapour } \\
\text { at } 350{ }^{\circ} \mathrm{C} / \text { vacuum } 800^{\circ} \mathrm{C}\end{array}$ & $\begin{array}{l}5 \times 10^{-4} \text { Torr, } 350 \\
{ }^{\circ} \mathrm{C}\end{array}$ & TEM & $\begin{array}{l}\text { Island nucleation rate } \\
\text { faster on (111) than } \\
(110) \text { or }(100)\end{array}$ \\
\hline $\begin{array}{l}\text { Zhou } \\
(2005)\end{array}$ & $70-80 \mathrm{~nm}$ & $\begin{array}{l}\text { Annealing in vacuum at } 550 \\
{ }^{\circ} \mathrm{C}\end{array}$ & $\begin{array}{l}5 \times 10^{-5} \text { Torr, } \\
350-900{ }^{\circ} \mathrm{C}\end{array}$ & TEM & $\begin{array}{l}\text { Temperature-dependent } \\
\text { shape and oxidation rate } \\
\text { of the oxide islands. }\end{array}$ \\
\hline $\begin{array}{l}\text { Zhou } \\
(2005)\end{array}$ & $70-80 \mathrm{~nm}$ & $\begin{array}{l}\text { Annealing in } \mathrm{CH}_{4} \mathrm{O} \text { vapour } \\
\text { at } 350{ }^{\circ} \mathrm{C} / \text { vacuum } 800{ }^{\circ} \mathrm{C}\end{array}$ & $\begin{array}{l}5 \times 10^{-4} \text { Torr, } 350 \\
{ }^{\circ} \mathrm{C}\end{array}$ & TEM & $\begin{array}{l}\text { Island nucleation rate } \\
\text { faster on (111) than } \\
(110) \text { or }(100)\end{array}$ \\
\hline Lampimaki ${ }^{24 \mathrm{I}}$ & - & $\begin{array}{l}\mathrm{Ar}^{+} \text {bombardment, anneal- } \\
\text { ing at } 700{ }^{\circ} \mathrm{C}\end{array}$ & $\begin{array}{l}2.8 \times 10^{-2}-160 \\
\text { Torr, } 30-100{ }^{\circ} \mathrm{C}\end{array}$ & $\begin{array}{l}\text { XPS, } \\
\text { XAS, } \\
\text { STM }\end{array}$ & $\begin{array}{l}\text { Island formation on top } \\
\text { of the missing-row recon- } \\
\text { struction for } \mathrm{O} / \mathrm{Cu}(100)\end{array}$ \\
\hline $\begin{array}{l}\text { Lahtonen } 116 \\
(2008)\end{array}$ & $0.5 \mathrm{~mm}$ & $\begin{array}{l}\mathrm{Ar}^{+} \text {bombardment, anneal- } \\
\text { ing at } 430{ }^{\circ} \mathrm{C}\end{array}$ & $\begin{array}{l}6 \times 10^{-7} \text { Torr and } \\
2.8 \times 10^{-2} \text { Torr, } \\
T=100^{\circ} \mathrm{C}\end{array}$ & STM & $\begin{array}{l}\text { Surface } \\
\text { tion and oxide island } \\
\text { formation at high } \mathrm{O}_{2} \\
\text { exposure. }\end{array}$ \\
\hline $\begin{array}{l}\text { Zhou } \\
(2009)\end{array}$ & $70 \mathrm{~nm}$ & $\begin{array}{l}\text { Annealing in } \mathrm{Ar} / \mathrm{H}_{2} \text { at } 700 \\
{ }^{\circ} \mathrm{C}\end{array}$ & $\begin{array}{l}5 \times 10^{-5} \text { Tor, } 700 \\
{ }^{\circ} \mathrm{C}\end{array}$ & TEM & $\begin{array}{l}\mathrm{Cu}_{2} \mathrm{O} \text { islands, } 200 / 500 \\
\mathrm{~nm} \text { side. Epitaxial } \\
\text { growth with inclined } \\
\mathrm{Cu}_{2} \mathrm{O} / \mathrm{Cu} \text { edges. }\end{array}$ \\
\hline $\begin{array}{l}\text { Zhou } \\
(2012)\end{array}$ & $50 \mathrm{~nm}$ & Annealing in $\mathrm{H}_{2}$ at $600{ }^{\circ} \mathrm{C}$ & $\begin{array}{l}5 \times 10^{-5} \text { Tor, } 350 \\
{ }^{\circ} \mathrm{C}\end{array}$ & TEM & $\begin{array}{l}\text { Step-edge induced oxide } \\
\text { growth. }\end{array}$ \\
\hline
\end{tabular}




\begin{tabular}{|l|l|l|l|l|l|}
\hline $\begin{array}{l}\text { Zhou } \\
(2013)\end{array}$ & $50 \mathrm{~nm}$ & Annealing in $\mathrm{H}_{2}$ at $600{ }^{\circ} \mathrm{C}$ & $\begin{array}{l}1 \times 10^{-3} \text { Tor, } 550 \\
{ }^{\circ} \mathrm{C}\end{array}$ & TEM & $\begin{array}{l}\mathrm{Cu}_{2} \mathrm{O} \text { islands grow on an } \\
\text { oxide wetting layer nu- } \\
\text { cleated on surface steps. }\end{array}$ \\
\hline
\end{tabular}

Table 3: Experimental results of copper oxide formation in ultra-high vacuum on $\mathrm{Cu}(100)$. Experimental conditions and techniques have been listed, together with a summary of the main result of each study.

\subsection{Oxide nano-islands: $\mathrm{Cu}(110)$}

The islands formed on $\mathrm{Cu}(110)$ single crystals after being exposed to low pressure oxygen $\left(P \sim 10^{-4}\right.$ Torr) are also found to be epitaxial with the substrate ${ }^{182}$. The island morphology and the time required to reach saturation density depend on temperature, with higher temperatures requiring much shorter time to saturation. Between 450 and $650{ }^{\circ} \mathrm{C}$ the lateral size of the islands is almost constant $(200-250$ $\mathrm{nm})$, however the islands were found to thicken considerably $(24-40 \mathrm{~nm})$ beneath the $\mathrm{Cu}$ surface, showing that the rise in temperature greatly enhances the interfacial diffusion of oxygen 257 . At 700 ${ }^{\circ} \mathrm{C}$, the (110) surface of clean copper roughens with a step height of $\sim 10 \mathrm{~nm} 258$. Exposure to oxygen of this rough surface shows the formation of a higher density of oxide islands with a fast nucleation rate but slower lateral growth than for smooth surfaces. This comparison between smooth and rough surfaces supports the idea that the kinetics of nucleation and growth of islands is dependent on the surface diffusion of oxygen atoms on the surface (see Sec. 5.4).

\begin{tabular}{|c|c|c|c|c|c|}
\hline Reference & $\begin{array}{l}\text { Sample } \\
\text { thickness }\end{array}$ & Surface Preparation & $\begin{array}{l}\text { Exp. Condi- } \\
\text { tions }\end{array}$ & Technique & Result \\
\hline $\begin{array}{l}\text { Zhou }^{259} \\
(2002)\end{array}$ & $70 \mathrm{~nm}$ & $\begin{array}{l}\text { Annealing in } \mathrm{CH}_{4} \mathrm{O} \text { vapour } \\
\text { at } 350{ }^{\circ} \mathrm{C}, 5 \times 10-5 \text { Tor }\end{array}$ & $\begin{array}{l}8 / 1 \times 10^{-4} \text { Tor at } \\
600{ }^{\circ} \mathrm{C}\end{array}$ & TEM & $\begin{array}{l}\text { Rod-shaped } 20 \mathrm{~nm} \text {-thick } \\
\text { islands. }\end{array}$ \\
\hline $\begin{array}{l}\text { Zhou } 182 \\
(2003)\end{array}$ & $70 \mathrm{~nm}$ & $\begin{array}{l}\text { Annealing in } \mathrm{CH}_{4} \mathrm{O} \text { vapour } \\
\text { at } 350{ }^{\circ} \mathrm{C}\end{array}$ & $\begin{array}{l}5 \times 10^{-4} \text { Tor, } 300 \\
{ }^{\circ} \mathrm{C} \text { and } 450^{\circ} \mathrm{C}\end{array}$ & TEM & $\begin{array}{l}\text { Faster initial oxidation } \\
\text { rate than } \mathrm{Cu}(100)\end{array}$ \\
\hline $\begin{array}{l}\text { Zhou } \\
(2004)\end{array}$ & $70 \mathrm{~nm}$ & $\begin{array}{l}\text { Annealing in } \mathrm{CH}_{4} \mathrm{O} \text { vapour } \\
\text { at } 350{ }^{\circ} \mathrm{C}\end{array}$ & $\begin{array}{l}5 \times 10^{-4} \text { Tor, } 350 \\
{ }^{\circ} \mathrm{C} \text { and } 750^{\circ} \mathrm{C}\end{array}$ & TEM & $\begin{array}{l}\text { Higher density and } \\
\text { slower lateral growth } \\
\text { rate of islands on } \\
\text { rougher } \mathrm{Cu}(110) \text { sur- } \\
\text { faces. }\end{array}$ \\
\hline $\begin{array}{l}\text { Zhou }^{257} \\
(2004)\end{array}$ & $70 \mathrm{~nm}$ & $\begin{array}{l}\text { Annealing in } \mathrm{CH}_{4} \mathrm{O} \text { vapour } \\
\text { at } 350^{\circ} \mathrm{C}\end{array}$ & $\begin{array}{l}5 \times 10^{-4} \text { Tor, } 750 \\
{ }^{\circ} \mathrm{C}\end{array}$ & TEM & $\begin{array}{l}\text { Faster oxidation at } \\
\text { higher temperatures. }\end{array}$ \\
\hline $\begin{array}{l}\text { Zhou } \\
(2005)\end{array}$ & $70-80 \mathrm{~nm}$ & $\begin{array}{l}\text { Annealing in } \mathrm{CH}_{4} \mathrm{O} \text { vapour } \\
\text { at } 350{ }^{\circ} \mathrm{C} / \text { vacuum } 800^{\circ} \mathrm{C}\end{array}$ & $\begin{array}{l}5 \times 10^{-4} \text { Tor, } 350 \\
{ }^{\circ} \mathrm{C}\end{array}$ & TEM & $\begin{array}{l}\text { Island nucleation rate } \\
\text { faster on (111) than } \\
(110) \text { or }(100)\end{array}$ \\
\hline $\begin{array}{l}\text { Zhou } \\
(2005)\end{array}$ & $70-80 \mathrm{~nm}$ & $\begin{array}{l}\text { Annealing in vacuum at } 550 \\
{ }^{\circ} \mathrm{C}\end{array}$ & $\begin{array}{l}5 \times 10^{-5} \text { Tor, } \\
350-900{ }^{\circ} \mathrm{C}\end{array}$ & TEM & $\begin{array}{l}\text { Temperature-dependent } \\
\text { shape and oxidation rate } \\
\text { of the oxide islands. }\end{array}$ \\
\hline $\begin{array}{l}\text { Zhou } \\
(2005)\end{array}$ & $70-80 \mathrm{~nm}$ & $\begin{array}{l}\text { Annealing in } \mathrm{CH}_{4} \mathrm{O} \text { vapour } \\
\text { at } 350{ }^{\circ} \mathrm{C} / \text { vacuum } 800{ }^{\circ} \mathrm{C}\end{array}$ & $\begin{array}{l}5 \times 10^{-4} \text { Tor, } 350 \\
{ }^{\circ} \mathrm{C}\end{array}$ & TEM & $\begin{array}{l}\text { Island nucleation rate } \\
\text { faster on (111) than } \\
(110) \text { or }(100)\end{array}$ \\
\hline
\end{tabular}

Table 4: Experimental results of copper oxide formation in ultra-high vacuum on $\mathrm{Cu}(110)$. Experimental conditions and techniques have been listed, together with a summary of the main result of each study.

\subsection{Oxide nano-islands: $\mathrm{Cu}(111)$}

At room temperature the oxidation of $\mathrm{Cu}(111)$ also proceeds through the formation of epitaxial oxide islands with a $5 \times 6$ lattice misfit $117 \sqrt{209 \mid 260}$ which coalesce with continuous oxygen exposure. Three processes of oxide formation are observed in this regime ${ }^{117 \mid 209}$ (Fig. 8): growth from step edges, interrace growth $(\sim 1.2 \AA$ below the terrace surface) from vacancy islands and growth of on-terrace 
oxide. The formation of randomly placed islands at low temperature agrees well with the existence of a disordered underlying structure observed for low-coverage oxygen adsorption and analysed in Sec. 4.3 . At higher temperatures ${ }^{2091260}$ fast formation of the oxide and fast lateral growth leads to the formation of a two-dimensional oxide structure. This uniform growth is templated by the distorted-hexagonal surface reconstruction shown in Sec. $4.3^{209}$.

Zhou et al. observed an interesting phenomenon at intermediate temperatures: the islands nucleate close to existing islands, anisotropically elongating along the [110] direction in a percolating manner, as shown in Fig. 9 .
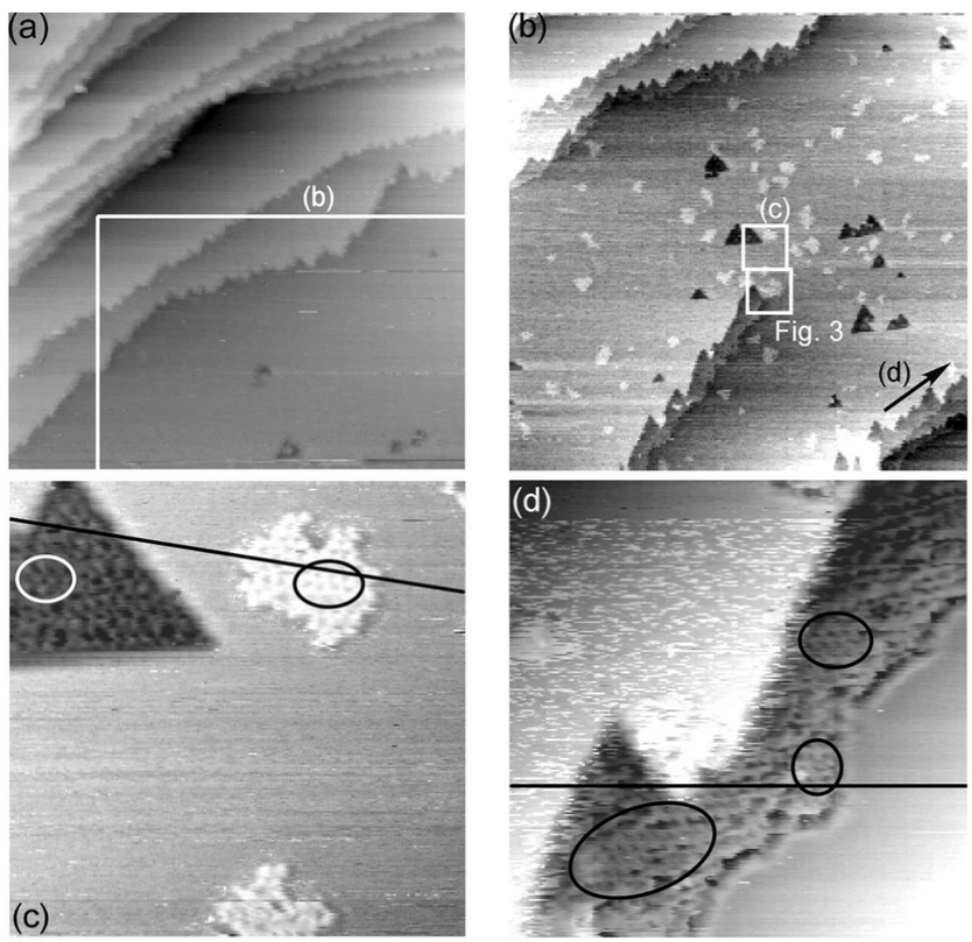

Figure 8: Structures observed with STM by Matsumoto et al. ${ }^{[209}$ when oxidising a $\mathrm{Cu}(111)$ surface with step edges (visible in panel a). In-terrace and on-terrace oxides are visible in panel b, and atomically resolved in panel c. In-terrace oxide is darker and on-terrace oxide lighter than the clean copper surface. Panel d shows the oxide which grows at the edge of the terrace. The area show in panel a,b is $2000 \times 2000 \AA^{2}$, in panel c,d is $200 \times 200 \AA^{2}$. The square in panel a indicates part of the area shown in $b$. Squares and the arrow in $b$ indicate the areas shown in $c$ and $d$.

This 'discontinuous-branched' shape has been investigated using kinetic Monte Carlo techniques ${ }^{261}$, and it appears to be related to restricted diffusion of oxygen on the surface, which might then be related to the surface being reconstructed to the '29' or ' 44 ' structures, which are fairly corrugated (they extend up to $3.1 \AA$ over the clean $\mathrm{Cu}(111)$ surface).

\begin{tabular}{|c|c|c|c|c|c|}
\hline Reference & $\begin{array}{l}\text { Sample } \\
\text { thickness }\end{array}$ & Surface Preparation & $\begin{array}{l}\text { Exp. Condi- } \\
\text { tions }\end{array}$ & Technique & Result \\
\hline $\begin{array}{l}\text { Lawless } 262 \\
(1956)\end{array}$ & - & Electropolishing & $\begin{array}{l}P=0.8-760 \\
\text { Torr, } T=170- \\
450{ }^{\circ} \mathrm{C}\end{array}$ & XRD & $\begin{array}{l}\text { Epitaxial } \mathrm{Cu}_{2} \mathrm{O} \text { oxide, } \\
\text { disordered } \mathrm{CuO} \text {. }\end{array}$ \\
\hline $\begin{array}{l}\text { Goulden } 227 \\
(1976)\end{array}$ & $\begin{array}{l}250-400 \\
\mu \mathrm{m}\end{array}$ & $\begin{array}{l}\text { Polishing in orthophospho- } \\
\text { ric acid at } 1.4 \mathrm{~V}\end{array}$ & $\begin{array}{l}8 \times 10^{-4} \text { Torr, } \\
T=250-400^{\circ} \mathrm{C}\end{array}$ & TEM & Epitaxial oxide islands. \\
\hline $\begin{array}{l}\mathrm{Ho}^{203} \\
(1978)\end{array}$ & - & $\begin{array}{l}\text { Annealing in vacuum at } 300 \\
{ }^{\circ} \mathrm{C}\end{array}$ & $\begin{array}{l}10^{-4}-10^{-7} \text { Torr } \\
T=350^{\circ} \mathrm{C}\end{array}$ & TEM & $\begin{array}{l}\text { Epitaxial } \\
\text { growth. }\end{array}$ \\
\hline
\end{tabular}




\begin{tabular}{|c|c|c|c|c|c|}
\hline $\begin{array}{l}\text { Dubois }^{114} \\
(1982)\end{array}$ & - & Annealing in $\mathrm{H}_{2}$ at $630{ }^{\circ} \mathrm{C}$ & $\begin{array}{l}1 \times 10^{-3} \text { Torr, } \\
T=525^{\circ} \mathrm{C}\end{array}$ & EM & $\begin{array}{l}\text { Epitaxial oxide islands } \\
\text { on defect sites. }\end{array}$ \\
\hline $\begin{array}{l}\text { Milne } \\
(1984)\end{array}$ & $0.05 \mu \mathrm{m}$ & Polishing, annealing & $\begin{array}{l}P=10^{-5}-5 \times \\
10^{-4} \text { Torr, } T= \\
300{ }^{\circ} \mathrm{C}\end{array}$ & $\begin{array}{l}\text { RHEED, } \\
\text { TEM }\end{array}$ & $\begin{array}{l}\text { Formation of epitaxial } \\
\text { oxide islands. }\end{array}$ \\
\hline $\begin{array}{l}\operatorname{Rauh}^{263} \\
(1993)\end{array}$ & $50 \mathrm{~nm}$ & Deposition by dc heating. & $\begin{array}{l}\mathrm{O}_{2}, P=7.5 \times \\
10^{-4}-9 \times 10^{-2} \\
\text { Tor, } T=105^{\circ} \mathrm{C}, \\
400 \mathrm{~min}\end{array}$ & Ellipsom. & $\begin{array}{l}\text { Formation of a } \mathrm{Cu}_{2} \mathrm{O} \\
\text { film }\end{array}$ \\
\hline $\begin{array}{l}\text { Matsumoto } \\
(2001)\end{array}$ & - & $\begin{array}{l}\mathrm{Ar}^{+} \text {sputtering and vacuum } \\
\text { annealing at } 500^{\circ} \mathrm{C}\end{array}$ & $\begin{array}{l}P=10^{-7}-10^{-5} \\
\text { Torr, RT }\end{array}$ & $\begin{array}{l}\text { STM, } \\
\text { LEED }\end{array}$ & $\begin{array}{l}\text { Growth of oxide from } \\
\text { step edges. }\end{array}$ \\
\hline $\begin{array}{l}\text { Zhou } \\
(2005)\end{array}$ & $70-80 \mathrm{~nm}$ & $\begin{array}{l}\text { Annealing in } \mathrm{CH}_{4} \mathrm{O} \text { vapour } \\
\text { at } 350{ }^{\circ} \mathrm{C} / \text { vacuum } 800^{\circ} \mathrm{C}\end{array}$ & $\begin{array}{l}5 \times 10^{-4} \text { Tor, } 350 \\
{ }^{\circ} \mathrm{C}\end{array}$ & TEM & $\begin{array}{l}\text { Island nucleation rate } \\
\text { faster on (111) than } \\
\text { (110) or }(100)\end{array}$ \\
\hline $\begin{array}{l}\text { Zhou } \\
(2005)\end{array}$ & $70-80 \mathrm{~nm}$ & $\begin{array}{l}\text { Annealing in vacuum at } 550 \\
{ }^{\circ} \mathrm{C}\end{array}$ & $\begin{array}{l}5 \times 10^{-5} \text { Tor, } \\
350-900{ }^{\circ} \mathrm{C}\end{array}$ & TEM & $\begin{array}{l}\text { Temperature-dependent } \\
\text { shape and oxidation rate } \\
\text { of the oxide islands. }\end{array}$ \\
\hline $\begin{array}{l}\text { Zhou } \\
(2005)\end{array}$ & $70-80 \mathrm{~nm}$ & $\begin{array}{l}\text { Annealing in } \mathrm{CH}_{4} \mathrm{O} \text { vapour } \\
\text { at } 350{ }^{\circ} \mathrm{C} / \text { vacuum } 800{ }^{\circ} \mathrm{C}\end{array}$ & $\begin{array}{l}5 \times 10^{-4} \text { Tor, } 350 \\
{ }^{\circ} \mathrm{C}\end{array}$ & TEM & $\begin{array}{l}\text { Island nucleation rate } \\
\text { faster on (111) than } \\
(110) \text { or }(100)\end{array}$ \\
\hline $\begin{array}{l}\text { Zhou } \\
(2008)\end{array}$ & - & $\begin{array}{l}\text { Annealing in vacuum at } 800 \\
{ }^{\circ} \mathrm{C}\end{array}$ & $\begin{array}{l}3 \times 10^{-4} \text { Tor, } 900 \\
{ }^{\circ} \mathrm{C}\end{array}$ & TEM & $\begin{array}{l}\text { Growth of oxide hollow } \\
\text { pyramidal islands. }\end{array}$ \\
\hline $\begin{array}{l}\text { Zhou }^{260} \\
(2009)\end{array}$ & $60 \mathrm{~nm}$ & $\begin{array}{l}\text { Annealing in } \mathrm{CH}_{4} \mathrm{O} \text { vapour } \\
\text { at } 350{ }^{\circ} \mathrm{C} / \text { vacuum } 800{ }^{\circ} \mathrm{C}\end{array}$ & $\begin{array}{l}5 \times 10^{-4} \text { Tor, } 350 \\
{ }^{\circ} \mathrm{C}\end{array}$ & TEM & $\begin{array}{l}\text { Epitaxial } \mathrm{Cu}_{2} \mathrm{O} \sim 2.5 \\
\text { nm-high islands. }\end{array}$ \\
\hline $\begin{array}{l}\text { Leon } 117 \\
(2012)\end{array}$ & $\overline{-}$ & $\begin{array}{l}\mathrm{Ar}^{+} \text {sputtering and } 550{ }^{\circ} \mathrm{C} \\
\text { heating }\end{array}$ & $\begin{array}{l}P=10^{-7} \text { Torr, } \\
\text { RT, pulse injec- } \\
\text { tion of air }\end{array}$ & $\begin{array}{l}\text { AES, } \\
\text { STM }\end{array}$ & $\begin{array}{l}\text { Oxide growth from step } \\
\text { edges. }\end{array}$ \\
\hline
\end{tabular}

Table 5: Experimental results of copper oxide formation in ultra-high vacuum on $\mathrm{Cu}(111)$. Experimental conditions and techniques have been listed, together with a summary of the main result of each study.

\subsection{Nano-island formation kinetics}

A number of models have been proposed to explain the kinetics governing the initial stages of oxide growth, from island nucleation to their coalescence.

The mechanism of nucleation and initial growth of oxide islands on a clean $\mathrm{Cu}$ surface has been proposed in terms of 'capture zones', a well-established idea in non-homogeneous film formation theory 264265 . In this interpretation, schematically shown in Fig. 10 a, oxygen atoms landing in a capture zone, i.e. an area with radius $L_{d}$ surrounding the island, will likely aggregate with the island and contribute to island growth rather than nucleating new islands. Large 'capture zones' (i.e. large values of $L_{d}$ ) are associate with longer path lengths of surface oxygen diffusion. In this framework, the saturation number of islands that can be nucleated, $N_{\text {sat }}$, is expressed as 234 .

$$
N_{s a t}=\frac{1}{L_{d}^{2}}\left(1-e^{-k L_{d}^{2} t}\right),
$$

where $k$ is the initial island nucleation rate and $t$ is time. This model was found to fit well experimental data for oxidation of $\mathrm{Cu}(100)$ and $\mathrm{Cu}(110)^{234 \mid 242}$, as shown in Table 5.4. The smaller number of islands

\begin{tabular}{|c|c|c|c|}
\hline & $N_{\text {sat }}\left[\mu \mathrm{m}^{-2}\right]$ & $k\left[\mu \mathrm{m}^{-2} \mathrm{~min}^{-1}\right]$ & $L_{d}$ \\
\hline$(100)$ & 0.83 & 0.17 & 1.09 \\
\hline$(110)$ & 4.34 & 1.74 & 0.33 \\
\hline
\end{tabular}

nucleating on $\mathrm{Cu}(100)$ is related to a larger oxygen capture area, i.e. longer path lengths for surface 


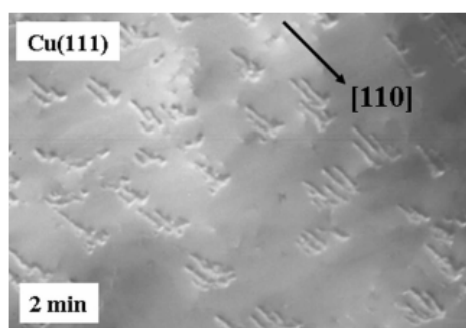

(a)

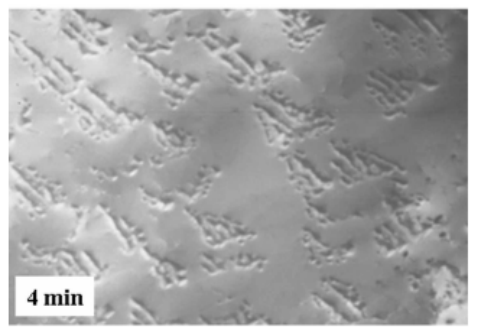

(c)

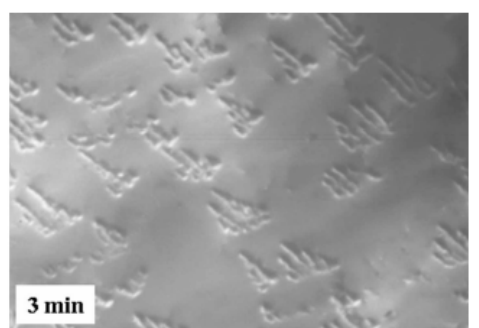

(b)

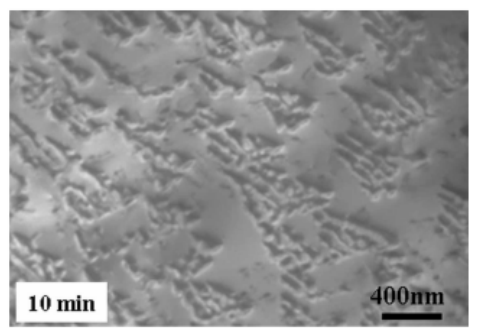

(d)

Figure 9: Percolating oxide growth on $\mathrm{Cu}(111)$ observed using in situ TEM imaging at $450{ }^{\circ} \mathrm{C}$. The oxidation partial pressure is $P=5 \times 10^{-4}$ Tor. The layer is formed by preferential nucleation of islands along the [110] direction, suggesting that between $350-450{ }^{\circ} \mathrm{C}$ the substrate transitions from a disordered to an ordered structure. Taken from Ref. 256 .

oxygen diffusion. This is consistent with the structure of the missing-row reconstructed $\mathrm{Cu}(100)$ surface, which is fairly smooth (it has a corrugation of $0.35 \AA^{138}$ ), see Sec. 4.1, thus favouring surface diffusion. Similarly, the short diffusion path length for $\mathrm{Cu}(110)$ is consistent with the added-row reconstruction which protrudes $\sim 1.5 \AA$ over the $\mathrm{Cu}$ surface 121147 (see Sec. 4.2). Nucleation is seen to be faster on $\mathrm{Cu}(110)$ than on $\mathrm{Cu}(100)$, see Table 5.4, and even faster on $\mathrm{Cu}(111)$ at $350^{\circ} \mathrm{C}^{256}$. The O-induced reconstruction of the $\mathrm{Cu}(111)$ surface has been reported to have a disordered surface overlayer at room temperature, with $\mathrm{O}$ and $\mathrm{Cu}$ atoms at different heights ${ }^{110 / 207}$ (see Sec 4.3). This could explain a shorter path length for oxygen diffusion on $\mathrm{Cu}(111)$ leading to a fast nucleation of a large number of oxide islands.

After island nucleation has reached saturation point, they start growing until coalescence. Island growth models based on oxygen impingement and surface diffusion (schematically represented in Fig. 10p) have been developed 233|266|267: oxygen surface diffusion initially dominates the oxide growth, and later oxygen direct impingement becomes significant when the oxide islands grow larger in size. In particular the model proposed by Yang et al. $\frac{233}{2}$ was found to fit well experimental data on $\mathrm{Cu}(100)$, with island growth proportional to $t^{1.3}$.

Another well established theory for the formation of thin films is the Avrami (or JMAK) nucleation model 268 270. It presumes isotropic and homogeneous nucleation of the islands and depends exponentially on time:

$$
X(t)=1-e^{-k t^{n}}
$$

where $X$ is the oxide thickness. $\mathrm{Cu}(100)$ fits this model ${ }^{242}$ with $k=1.9 \times 10^{-4}$ and $n=2$. The value of $k$ is much smaller than expected (typically it is $k=\pi / 3$ ), possibly because of the non-constant island nucleation in cuprous oxide (but rather following the relation in Eq. 1) and the non-linear island growth rate $\left(A(t) \propto t^{1.3}\right)$. Yang et al. modified the JMAK model in order to take into account these two factors and found an excellent fit with $\mathrm{Cu}(100)$ experimental data ${ }^{235}$.

Although the nucleation of islands is faster on $\mathrm{Cu}(110)$, the long term (> 60 minutes) oxidation of

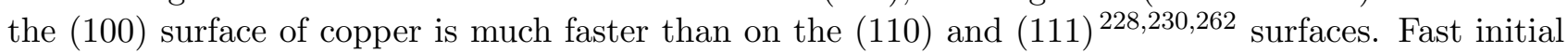




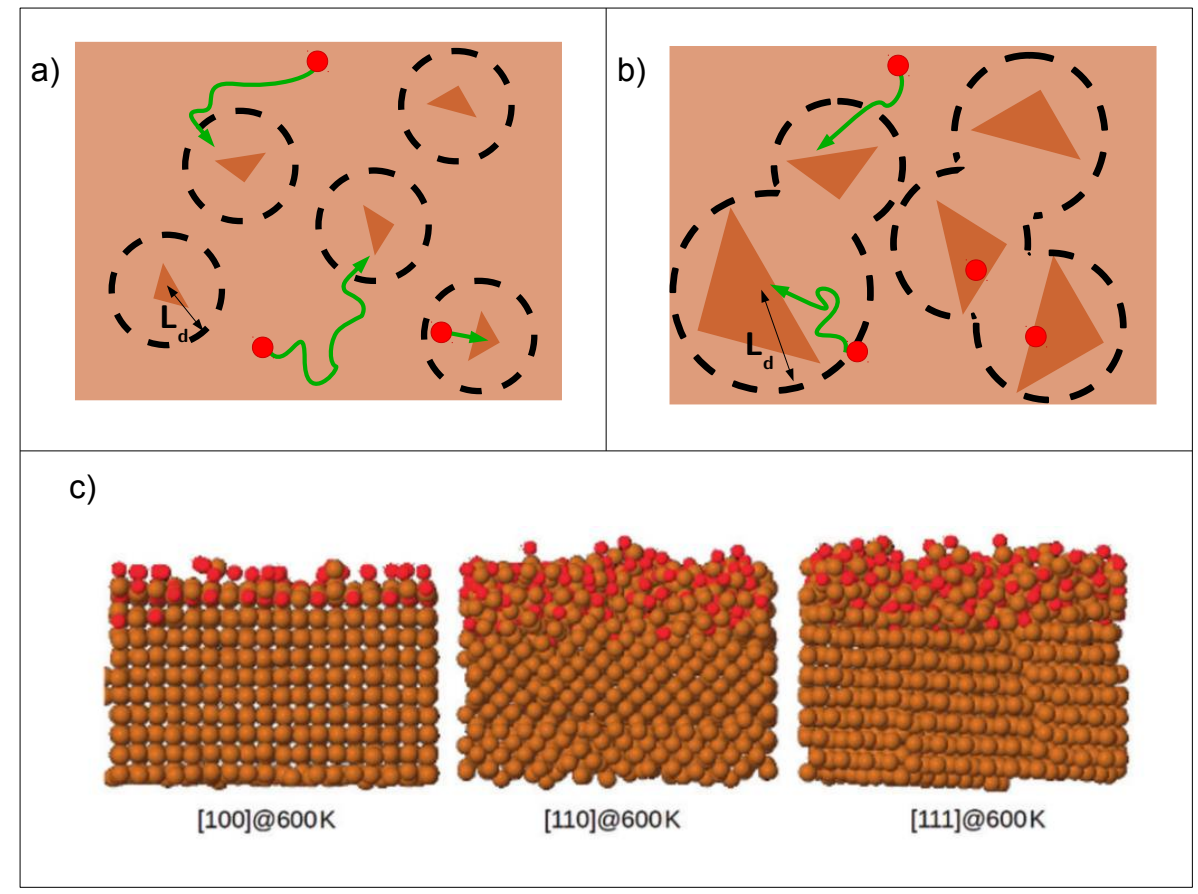

Figure 10: a) Schematic representation of the mechanism of island nucleation and growth according to the model in Eq. 1. The dashed circles represent the 'oxygen capture zones' of radius $\mathrm{L}_{d}$ around the oxide islands. Oxygen atoms (in red) diffuse on the surface until they enter a capture zone, when they are incorporated in an oxide island (represented as a brown triangle). b) Schematic representation of the mechanisms of island growth to coalescence. As the islands increase in size their areas of oxygen capture increase (black dashed line). Oxygen surface diffusion (green arrows) is still important, however direct impingement of oxygen atom in the islands is also more likely to occur. c) Oxidation of $\mathrm{Cu}(100)$, $\mathrm{Cu}(110)$ and $\mathrm{Cu}(111)$ copper surfaces using the ReaxFF force field at $T=300 \mathrm{~K}$ and $T=600 \mathrm{~K}$. $\mathrm{Cu}(111)$ is found to oxidise more easily than (110) and (100) and form a thicker oxide film. The amorphous nature of the formed oxide is clearly visible. Taken from Ref. ${ }^{271}$.

nucleation and growth of islands on $\mathrm{Cu}(110)$ and $\mathrm{Cu}(111)$ leads quickly to a thinner coalesced film, which then continues growing through oxygen diffusion through the oxide layer, a much slower process than surface diffusion. On the contrary, the slow nucleation of islands on $\mathrm{Cu}(100)$ leads to slower coalescence to a thicker oxide film with respect to the $\mathrm{Cu}(110)$ and $\mathrm{Cu}(111)$ and thus quicker oxide growth by means of surface diffusion.

The case of oxidation on $\mathrm{Cu}(111)$ at higher temperatures (over $550{ }^{\circ} \mathrm{C}$ ) is the only one where $\mathrm{Cu}_{2} \mathrm{O}$ two-dimensional thin film growth is observed $117 \mid 256$. The O-induced surface reconstruction of $\mathrm{Cu}(111)$ at high temperatures, as seen on Sec. 4.3, has a hexagonal morphology similar to the $\mathrm{Cu}_{2} \mathrm{O}(111)$ plane ${ }^{110207}$ which can act as a 'template' structure for the layered growth of the oxide.

A few computational studies have tried to obtain further insight into the kinetics of oxide growth, with limited success so far. The correct relative rates on the three low-index $\mathrm{Cu}$ surfaces have been obtained using molecular dynamics with ReaxFF, a bond order potential 271 . However the calculation led to the formation of a uniform amorphous thin film (as shown in Fig. 10;), thus not reproducing crystalline island formation as seen in experiments, and the role of the surface reconstruction was

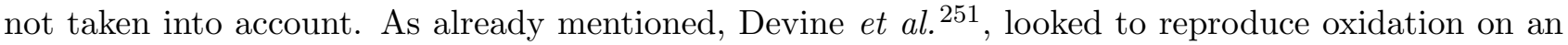
O-reconstructed $\mathrm{Cu}(100)$ surface, using molecular dynamics and a bond order potential. However, the process was too slow and the simulation too short for it to be modelled. 

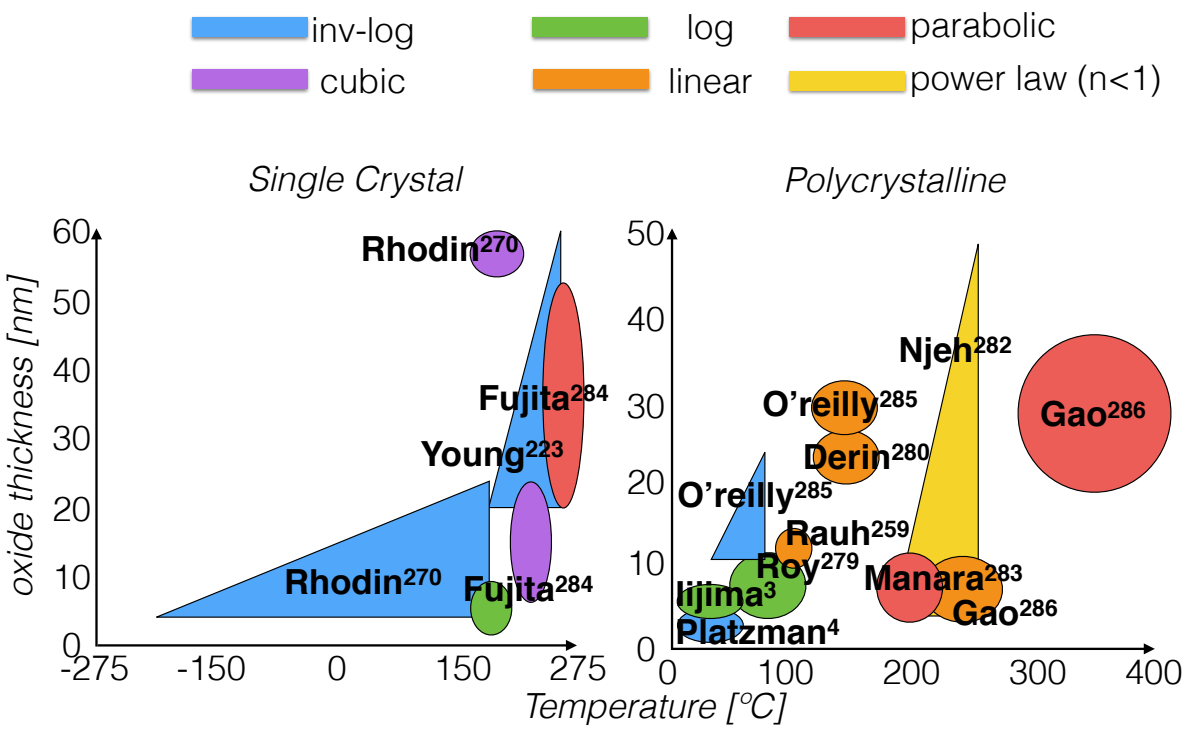

Figure 11: Overview of growth models for copper oxide present in the literature. The graphs show the oxide film thickness vs oxidation temperature for a number of experimental studies. The data have been divided into two categories, according the composition of the initial copper sample, single crystal or polycrystalline. They have also been colour coded according to the oxidation kinetic model which has been attributed to them. It can be seen that on the basis of these three parameters only (temperature, film thickness and initial sample structure) a single kinetic model cannot be identified.

\subsection{Long-term copper oxidation}

After nucleation, growth and coalescence of copper oxide islands, oxidation proceeds through the diffusion of oxygen atoms through the oxide and the character of the oxidation process changes.

The kinetics and mechanism of copper oxidation, after the exposure of the copper surface to oxygen flow for an extended period (up to 32 hours) have been extensively studied ${ }^{14|272| 273}$, however no consensus on a single rate law describing the oxidation dynamics has been established.

Clean copper surfaces have been found to oxidize at different rates, with the $\mathrm{Cu}(100)$ face reported to have the fastest rate of oxidation, at odds with the oxidation rates measured for the formation and growth of oxide nano-islands. Indeed, Young ${ }^{228}$ et al. and Gwathmey ${ }^{229}$ et al. found that the order of oxidation rate for the low-index surfaces is (100), (111), (110) with (100) the fastest oxidising facet, for a wide range of temperatures. Rhodin ${ }^{274}$ found instead the order to be (100), (110), (111) with (100). This difference in ordering could be due to several factors, for example the use of very different experimental analysis techniques. Gwathmey ${ }^{229}$ et al. used diffuse white light to analyse the oxidized surfaces, observing different interference colours corresponding to different oxide thicknesses, Young 228 et al. used ellipsometry which relies on a 'guess' of a surface model and Rhodin ${ }^{274}$ calculated the film thickness from weight changes in the sample. All three methods present some drawbacks (diffuse white light does not provide a value for the thickness and relies on visual checking of the surface colour, ellipsometry relies on a guess model and Rhodin's method depends on an accurate estimation of the effective area of the resulting oxide) and it is difficult to tell which of the three is more reliable. The difference observed could also be the result of environmental factors such as the presence of impurities or different sample preparations, which have been shown to lead to different resulting metal oxides $275 / 276$ 
which makes oxidizing metals very challenging to study.

Very large discrepancies are observed in models for oxidation rates, i.e. growth of thickness of the oxide as a function of time, and they are summarised in Fig 11. A number of theories have been proposed $^{277} \sqrt{280}$, mostly based on the Cabrera and Mott 281 theory and they postulate that, under the assumption of uniform epitaxial growth, the thickness of a metal oxide increases following an inverse logarithmic rate law for very thin films (up to $7.3 \mathrm{~nm}$ for $\mathrm{Cu}$ ) and a cubic law for thicker films (up to $1.5 \mu \mathrm{m})$. A number of works $\frac{228|274| 282 \mid 283}{}$ find qualitative agreement with the Cabrera-Mott theory, however linear oxide growth has been observed in other studies $263|284| 285$, as well as power $(n<1)^{286}$ or parabolic law 287 .

Many factors can affect the experimental measurements of oxide kinetics, such as the environment and the type of initial copper sample. Indeed, it was found that polycrystalline film oxidation kinetics is almost twice as slow as single crystal oxidation kinetics 285 . The oxidation temperature is another

factor $288+290$. O'Reilly ${ }^{289}$ et al. found for a polycrystalline sample in dry synthetic air $\left(\mathrm{O}_{2} / \mathrm{Ar}\right.$ mixture $)$ that at temperatures between 250 and $500{ }^{\circ} \mathrm{C}$ the oxidation followed a cubic law, at $100{ }^{\circ} \mathrm{C}$ an inverse $\log$ rate and at $150{ }^{\circ} \mathrm{C}$ a linear growth rate. Gao ${ }^{290}$ et al. found a linear oxidation rate between $200-250{ }^{\circ} \mathrm{C}$ with a fine-grained $\mathrm{Cu}_{2} \mathrm{O}$ being the resultant oxide, and parabolic above that, with $\mathrm{CuO}$ the final oxidation product.

Although a lot of work has been performed in this field, it is clear from Fig. 11 that there is no consistency in the results obtained. Systematic work looking at the influence of crystal structure (single crystal, polycrystalline, different grain size), of the experimental set-up (humidity, temperature, oxygen pressure) and composition of the oxide product need to be performed in order to clarify where the contributions to these different oxidation rates originate from.

\subsection{Native oxidation of copper in ambient conditions}

Structural details of the room temperature oxidation of copper under ambient conditions, including the possible influence of humidity and crystal structure, are not very clear.

In order to study copper in ambient conditions (room-temperature, 1 atm pressure) precise measurement techniques are required, since surface oxide films are generally only a few nm thick. Experiments studying oxidation in these conditions have been performed for an enormous range of exposure times, between 30 minutes to 9 months, in air at ambient conditions (referred to as ambient air hereafter), obtaining results which are not always consistent (see Table 6). As we will see, the outcome of the studies differs in the thickness of the final oxide, in the presence or not of a $\mathrm{CuO}$ overlayer on top of the $\mathrm{Cu}_{2} \mathrm{O}$ oxide layer and in the order of formation of the oxides. The reason for this non-uniformity is probably to be found in the method of preparation of the film, on the type of film used (thin/bulk, polycrystalline/single crystal), the ambient humidity (which is rarely reported) and the surface roughness.

Native oxidation has been extensively studied in copper thin films (of the order of a few hundred $\mathrm{nms}$ ), because of the important role it plays in the passivation of nano-sized electronic copper parts, using XAS and XPS to identify the composition of the top layer and ellipsometry to measure the film thickness. Platzman et al. ${ }^{[4}$ proposed a three-stage oxidation mechanism involving: (a) the formation of a $\mathrm{Cu}_{2} \mathrm{O}$ layer, most likely due to $\mathrm{Cu}$ metal ionic transport toward the oxide-oxygen interface; (b) the formation of a $\mathrm{Cu}(\mathrm{OH})_{2}$ metastable overlayer, due to the interactions of $\mathrm{Cu}$ ions with hydroxyl groups present at the surface; and (c) the transformation of the $\mathrm{Cu}(\mathrm{OH})_{2}$ metastable phase to a more stable $\mathrm{CuO}$ layer. Indeed, the formation of a $\sim 2.0-5.0 \mathrm{Cu}_{2} \mathrm{O}$ layer first, followed by a $\sim$ $0.9-1.3 \mathrm{CuO}$ overlayer has been reported $3 / 4291 / 292$. However, Lim et al. ${ }^{276}$ showed that the texture and microstructure of a thin copper film have a direct influence on the oxidation products. When oxidising a sample with a columnar structure and small grains the $\mathrm{Cu}_{2} \mathrm{O} / \mathrm{CuO}$ bylayer was obtained, when oxidising a uniform sample with no obvious columnar structure and grain boundaries the cuprous 
oxide layer only was observed and oxidation was slower.

The oxidation of bulk copper studies was studied by means of XPS, XRD and ellipsometry, and the results obtained are mixed. A number of studies ${ }^{3 / 2931294}$ found only the formation of $\sim 1.6 \mathrm{~nm}$ thick $\mathrm{Cu}_{2} \mathrm{O}$ even after long exposure times. However, other studies of passivated $\mathrm{Cu}$ after exposure at roomtemperature air $\frac{\sqrt[2295]{29}}{2}$ observed the formation of a few $\mathrm{ML}$ of $\mathrm{CuO}$, which was found to start growing only after the $\mathrm{Cu}_{2} \mathrm{O}$ growth process has finished. The different results obtained by these experiments can be due to the texture and microstructure of the copper film 276 , by the surface roughness or by defects present at the surface. Indeed, the surface roughness of metal oxide surfaces has been shown to have a direct influence on their wetting properties towards water, which in turn could have a direct influence on the formation of the native oxide 296 . In particular, very smooth copper surfaces are hydrophobic while rough surfaces $(\sim 5 \mathrm{~nm}$-high roughness) are hydrophilic $\stackrel{297}{ }$. Furthermore the orientation of the crystallites at the surface influences the wetting properties and the distribution and coverage of water on the surface, especially in the case of copper 298 . Moreover, polycrystalline structures with nanosized grains have higher surface energy at the grain boundaries than structures that are made of micrometric grains or crystalline lattice, which in turns affect the wettability of the surface. 


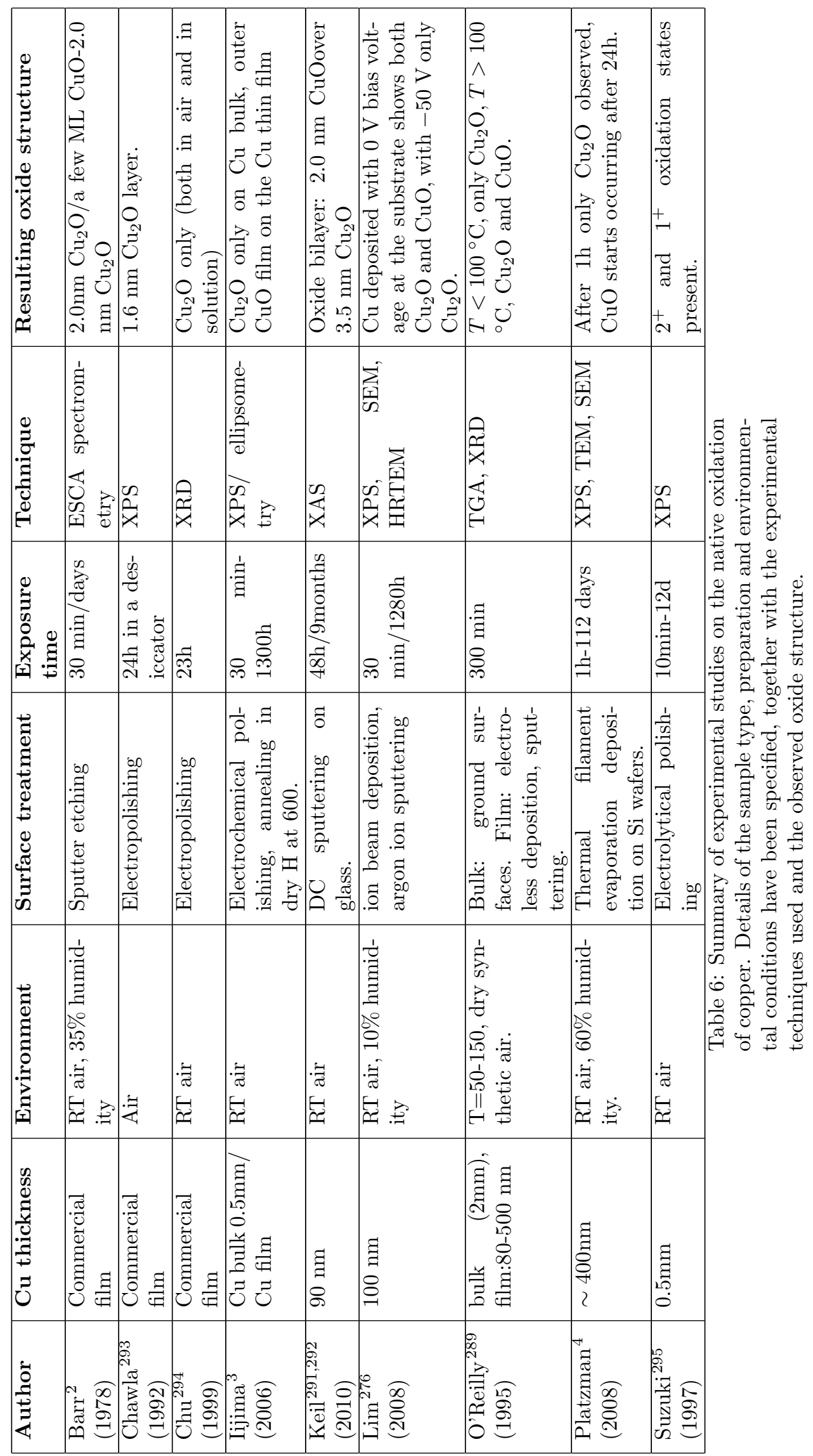




\subsection{Nucleation sites}

A number of studies have tried to establish the role of surface defects on the nucleation of the oxide, in order to understand whether island nucleation is a heterogeneous process, triggered by specific surface features, or a homogeneous process. While some metals and semimetals can grow oxide layers homogeneously without the aid of impurities or surface defects (such as $\mathrm{Ru}(0001)^{244}, \mathrm{Ag}(110)^{243}$ or

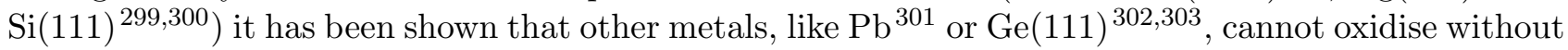
the presence of surface features (impurities or defects) which trigger the dissociation of $\mathrm{O}_{2}$ molecules.

For copper it has been shown ${ }^{11411612091255}$ that defect sites play a role in oxide island nucleation. Grain boundaries ${ }^{255}$, vacancy islands ${ }^{209}$ and the edges of pits ${ }^{254}$ are found to be nucleating sites for island formation, however no preferential nucleation sites have been found at dislocations, stacking faults or impurities ${ }^{113254255}$. The importance of step edges was initially inferred by Milne and Howie ${ }^{232}$, and it was then demonstrated on $\mathrm{Cu}(111)$ by means of STM and TEM ${ }^{117209}$. However, TEM work by Yang et al. ${ }^{[254255}$ showed that this is not the case on $\mathrm{Cu}(100)$ and $\mathrm{Cu}(110)$ films. It is indeed possible, considering the different nature of oxide formation on the three low-index surfaces, that different defects play a more or less important role in different oxide nucleation conditions.

More work is needed to clarify further the correlation between defect sites and oxide formation and remove doubts on whether small, non-structured dislocations and impurities have a role in the nucleation of copper oxide islands, and, from a theory point of view, why some type of defects seem more efficient at nucleating oxide islands than others.

\section{$5.8 \mathrm{CuO}$ formation}

$\mathrm{CuO}$ is expected to form after exposure of a copper surface to oxygen at high temperatures and

pressure ${ }^{39225}$. Much work has gone into understanding high temperature oxidation of copper $\left(>350^{\circ}\right)$ and it has been recently reviewed 304305 . Most work shows the growth of $\mathrm{CuO}$ on top of $\mathrm{Cu}_{2} \mathrm{O}$, following a parabolic rate law for the thickness as a function of time. However, no studies of the atomistic details of the formation of $\mathrm{CuO}$ at high temperatures have been performed to date.

In controlled conditions, evidence of a $\mathrm{CuO}$ overlayer was found by exposing a $\mathrm{Cu}$ sample to a controlled flow of $\mathrm{O}_{2}$ at high pressure and the dependence of oxidation on oxygen pressure was

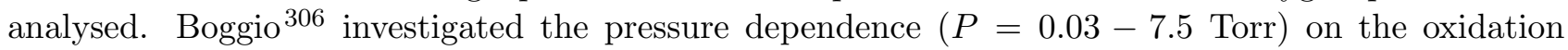
of $\mathrm{Cu}(111)$, and in particular the film thickness, using ellipsometry. The film growth (thought to be $\mathrm{Cu}_{2} \mathrm{O}$ ), after 90 minutes exposure at $21^{\circ}$, was related to the Cabrera-Mott expression of growth. However, a dramatic decrease in the oxidation rate with increased oxygen pressure was observed and related to the formation of a passivating $\mathrm{CuO}$ film at the oxide-oxygen interface. Pierson ${ }^{226}$ et al. looked at the reactivity of a number of noble metals when subject to a flow of gases. In the case of $\mathrm{Cu}$ in an $\mathrm{O}_{2}$ flow, the formation of oxidised structures was found to depend on the flow rate of $\mathrm{O}_{2}$. The formation of $\mathrm{Cu}_{2} \mathrm{O}$ (at oxygen partial pressure $\mathrm{p}\left(\mathrm{O}_{2}\right)=7.5 \times 10^{-5}$ Torr), $\mathrm{CuO}\left(\mathrm{p}\left(\mathrm{O}_{2}\right)=1.12 \times 10^{-3}\right.$ Torr) and metastable $\mathrm{Cu}_{4} \mathrm{O}_{3}\left(\mathrm{p}\left(\mathrm{O}_{2}\right)=1.5 \times 10^{-4}\right.$ Torr $)$, was observed by XRD analysis.

\section{Conclusion and discussion}

The oxidation of copper and the physical properties of the resulting oxides are fundamental scientific problems which are still not completely understood today. Since there has currently been a surge of interest in the use of copper oxide for catalysis, optoelectronics and gas sensing, the need for a detailed understanding of the surface structures of these oxides has become even more pressing. In addition, uncontrolled copper oxidation is still an issue in e.g. electronic applications, and understanding the oxide growth process is the first step towards mitigating it.

In this review we have discussed the state of the knowledge regarding the structure and formation 
of copper oxides and we have seen that the structural, optic and vibrational characteristics of bulk copper oxides are well understood. A good amount of computational work (mainly from DFT) has been performed on both $\mathrm{Cu}_{2} \mathrm{O}$ and $\mathrm{CuO}$, providing important information on the structures of the surfaces at different temperature and pressure conditions. A hexagonal structure presenting $\mathrm{Cu}$ surface vacancies was found to be the most stable on $\mathrm{Cu}_{2} \mathrm{O}$ and the stoichiometric (111) surface was the most stable for $\mathrm{CuO}$. Few experimental studies are available to either confirm or disprove these suggestions from theory. Considering the potential technological applications of these oxides, this is an area which should be looked at more with experimental techniques such as STM, XPS or LEED.

Many atomistic aspects of the formation of the oxides have been established. Indeed, the oxygeninduced surface reconstructions on copper surfaces with low Miller index are well known. In addition, STM studies have revealed certain atomic level details of the initial stages of $\mathrm{Cu}$ surface oxidation. Other experiments at low oxygen pressure show that the initial oxide growth happens through the formation of cuprous oxide islands which eventually coalesce. The kinetics of the oxide formation depends on the temperature and on the copper surface and it is dominated by oxygen surface diffusion and direct impingement in the first instance, and after coalescence by oxygen diffusion into the bulk.

There is however scope for further work as many fundamental aspects of copper oxidation are still unclear. In fact, there is no consensus on how the transition from oxygen-reconstructed copper surfaces to the onset of oxidation occurs, whether this is after the surface has been reconstructed or if the islands start forming on the clean surface. At least for the case of $\mathrm{Cu}(100)$ and $\mathrm{Cu}(110)$, there is good evidence that the onset of oxidation will occur after the formation of an O-reconstructed overlayer which affects the growth kinetics of the islands themselves. The precise understanding of the formation of these copper islands is not only important to understand the onset of oxidation, but also to exploit the oxide islands as nano-templates for technological applications. In order to do that, the precise mechanism of nucleation needs to be understood.

It is also unclear where the different behaviour between metals such as $\mathrm{Ag}$ or $\mathrm{Al}$, which grow uniform oxide layers, and copper stems from. The O-induced surface reconstructions of different fcc metals have been extensively studied $\frac{121}{121}$ and the differences found in their electronic structures 307 or surface configurations ${ }^{308}$ could provide hints to their different behaviour upon higher exposure to oxygen. However, dedicated theoretical studies to this aim have not been performed so far.

The kinetics of long-term oxide growth, both in controlled conditions and in ambient air is an issue that remains poorly understood. Copper oxide formation does not simply follow the Cabrera-Mott law, especially at the initial stages when oxide growth is not uniform across the surface. Many studies have been performed in order to establish the oxide formation kinetics at low temperatures, however they are difficult to compare to one another, because of the different conditions in use. Indeed temperature, humidity, oxygen partial pressure, structure of the initial copper film/coupon, the presence of defects and impurities seem to affect the growth of the oxide as well as the final oxide product. Moreover, the structure of copper oxide when grown in ambient air, which is very important to the practical uses of copper, is still not clearly understood, with the formation of a $\mathrm{CuO}$ overlayer on top of a $\mathrm{Cu}_{2} \mathrm{O}$ layer still being debated. Further systematic experimental studies, looking at disentagling the environmental factors influencing oxide growth are needed. Computationally, additional studies of copper and copper oxide surfaces and their interaction with the environment (e.g. water, $\mathrm{O}_{2}, \mathrm{~N}_{2}$ ) would provide valuable information in support of the experimental work. Work in this direction has recently been reported, e.g. water and hydroxide adsorption on $\mathrm{Cu}$ and $\mathrm{Cu}$ oxide $309+312$.

Part of the challenges that have been faced by scientists in studying these systems are due to the limitations of theoretical and experimental technology available to them. It is indeed clear that massive steps forward have been made since the first calorimetry experiments on $\mathrm{Cu}_{2} \mathrm{O}$ crystals, and nanometre scale resolution has been obtained with STM and TEM and structural atomistic structures can be explored with XPS and LEED. Moreover, development of experimental techniques, such as X-ray lasers with extremely high spatial and temporal resolution $\stackrel{313}{ }$ or near-ambient pressure photoelectron 
spectroscopy ${ }^{314}$ might enable mechanisms of initial stages of oxidation to be explored.

Computational techniques also present challenges from the point of view of accuracy of calculated structures and physical properties, as well as time length of molecular dynamics simulations. Moreover developments in theory, especially ab initio molecular dynamics, accelerated sampling techniques and more sophisticated non $a b$ initio approaches mean that similar studies on the first steps of oxidation are possible. Ab initio molecular dynamics, along with a free energy sampling approach has been used to examine the initial stages of $\mathrm{NaCl}$ dissolution in liquid water ${ }^{?}$ : it is not inconceivable that similar techniques could be applied to copper oxidation in ambient and even aqueous conditions.

Finally, another important challenge, is bridging the gap between highly controlled studies performed in ultra-high vacuum and work aiming to understand the formation of the oxide in industrially relevant conditions. At the moment, these two aspects of the oxidation problem are addressed using different techniques at different resolutions. In order to fully understand the oxidation of copper it is important to be able to relate the results obtained in these different conditions to one another and build a unified picture of the problem.

\section{Acknowledgements}

A.M.'s work is partly supported by the European Research Council under the European Union's Seventh Framework Programme (FP/2007-2013)/ERC Grant Agreement No. 616121 (HeteroIce project) and the Royal Society through a Wolfson Research Merit Award.

\section{References}

[1] M. Miodownik, Stuff Matters: The Strange Stories of the Marvellous Materials that Shape Our Man-made World, Penguin, 2014.

[2] T. L. Barr, J. Vac. Sci. Tech., 1977, 14, 660.

[3] J. Iijima, J. W. Lim, S. H. Hong, S. Suzuki, K. Mimura and A. Isshiki, Appl. Surf. Sci., 2006, $253,2825$.

[4] I. Platzman, R. Brener, H. Haick and R. Tannenbaum, J. Phys. Chem. C, 2008, 112, 1101.

[5] J. Song, L. L. Wang, A. Zibart and C. Koch, Metals, 2012, 2, 450.

[6] P. Szakalos, G. Hultquist and G. Wikmark, Electrochem. Sol. St. Lett., 2007, 10, C63.

[7] J. B. Reitz and E. I. Solomon, J. Am. Chem. Soc., 1998, 120, 11467.

[8] Y. Nakamura, H. Yoshioka, M. Miyayama, H. Yanagida, T. Tsurutani and Y. Nakamura, J. Electrochem. Soc., 1990, 137, 940.

[9] B. Rai, Solar Cells, 1988, 25, 265.

[10] B. K. Meyer, A. Polity, D. Reppin, M. Becker, P. Hering, P. J. Klar, T. Sander, C. Reindl, J. Benz, M. Eickhoff, C. Heiliger, M. Heinemann, J. Blaesing, A. Krost, S. Shokovets, C. Mueller and C. Ronning, Physica Stat. Sol. B, 2012, 249, 1487.

[11] M. S. Hunter and P. Fowle, J. Electrochem. Soc., 1956, 103, 482.

[12] H. Lu, E. Gusev, E. Garfunkel and T. Gustafsson, Surf. Sc., 1996, 351, 111.

[13] C. Palacio and H. J. Mathieu, Surf. Interf. Anal., 1990, 16, 178.

[14] K. R. Lawless, Rep. Prog. Phys., 1974, 37, 231.

[15] H. J. Freund, H. Kuhlenbeck and V. Staemmler, Rep. Prog. Phys., 1996, 59, 283. 
[16] U. Diebold, S. C. Li and M. Schmid, in Annual Review Of Physical Chemistry, ed. S. Leone, P. Cremer, J. Groves, M. Johnson and G. Richmond, Annual Reviews, 2010, vol. 61, p. 129.

[17] G. A. Somorjai, Introduction to Surface Chemistry and Catalysis, Wiley, 1994.

[18] A. Gross, Theoretical Surface Science: A Microscopic Perspective ; with 11 Tables and 32 Exercises, Springer, 2003.

[19] K. Wandelt, Surface and Interface Science, Wiley, 2012.

[20] G. Bracco and B. Holst, Surf. Sci. Techniques, Springer, 2013.

[21] D. Frenkel and B. Smit, Understanding Molecular Simulation: From Algorithms to Applications, Academic Press, 2002 .

[22] J. Behler, in Multiscale Simulation Methods in Molecular Sciences, ed. J. Grotendorst, N. Attig, S. Bluegel and D. Marx, Julich Supercomputing Centre, 2009, vol. 42, p. 247.

[23] W. J. Szlachta, A. P. Bartók and G. Csányi, Phys. Rev. B, 2014, 90, 104108.

[24] A. C. T. van Duin, S. Dasgupta, F. Lorant and W. A. Goddard, J. Phys. Chem. A, 2001, $105,9396$.

[25] A. Warshel and M. Levitt, J. Mol. Biol., 1976, 103, 227.

[26] R. A. Friesner, Proc. Nat. Acad. Sc., 2005, 102, 6648.

[27] W. Kohn and L. J. Sham, Phys. Rev., 1965, 140, A1133.

[28] P. Hohenberg and W. Kohn, Phys. Rev., 1964, 136, B864.

[29] V. Brazdova and D. R. Bowler, Atomistic Computer Simulations: A Practical Guide, Wiley, 2013.

[30] S. Curtarolo, G. L. W. Hart, M. B. Nardelli, N. Mingo, S. Sanvito and O. Levy, Nat. Mat., $2013,12,191$.

[31] K. Burke, J. Chem. Phys., 2012, 136, 150901.

[32] B. Himmetoglu, A. Floris, S. de Gironcoli and M. Cococcioni, Int. J. Quant. Chem., 2014, $114,14$.

[33] J. P. Perdew and A. Zunger, Phys. Rev. B, 1981, 23, 5048.

[34] J. Heyd, G. E. Scuseria and M. Ernzerhof, J. Chem. Phys., 2003, 118, 8207.

[35] J. Paier, R. Hirschl, M. Marsman and G. Kresse, J. Chem. Phys., 2005, 122, 234102.

[36] F. Aryasetiawan and O. Gunnarsson, Rep. Prog. Phys., 1998, 61, 237.

[37] J. C. Slater, Phys. Rev., 1930, 35, 210.

[38] J. C. Slater and G. F. Koster, Phys. Rev., 1954, 94, 1498.

[39] G. Honjo, J. Phys. Soc. Japan, 1949, 4, 330.

[40] S. P. Tandon and J. P. Gupta, Phys. Stat. Sol., 1970, 37, 43.

[41] J. Ghijsen, L. H. Tjeng, J. Vanelp, H. Eskes, J. Westerink, G. A. Sawatzky and M. T. Czyzyk, Phys. Rev. B, 1988, 38, 11322 .

[42] K. P. Bohnen, R. Heid, L. Pintschovius, A. Soon and C. Stampfl, Phys. Rev. B, 2009, 80, 134304.

[43] R. Mittal, S. L. Chaplot, S. K. Mishra and P. P. Bose, Phys. Rev. B, 2007, 75, 174303.

[44] A. Hallil, J.-M. Raulot and M. Cherkaoui, Comp. Mat. Sci., 2014, 81, 366.

[45] J. Robertson, Phys. Rev. B, 1983, 28, 3378.

[46] A. Sanson, Sol. State Comm., 2011, 151, 1452.

[47] M. M. Islam, B. Diawara, V. Maurice and P. Marcus, J. Mol. Struct.-Theochem, 2009, 903, 41. 
[48] A. Martinez-Ruiz, M. G. Moreno and N. Takeuchi, Sol. State Sci., 2003, 5, 291.

[49] A. Soon, M. Todorova, B. Delley and C. Stampfl, Phys. Rev. B, 2006, 73, 165424.

[50] E. Ruiz, S. Alvarez, P. Alemany and R. A. Evarestov, Phys. Rev. B, 1997, 56, 7189.

[51] H. Raebiger, S. Lany and A. Zunger, Phys. Rev. B, 2007, 76, 045209.

[52] R. Laskowski, P. Blaha and K. Schwarz, Phys. Rev. B, 2003, 67, 8.

[53] A. Filippetti and V. Fiorentini, Phys. Rev. B, 2005, 72, 8.

[54] A. Onsten, M. Gothelid and U. O. Karlsson, Surf. Sci., 2009, 603, 257.

[55] J. P. Hu, D. J. Payne, R. G. Egdell, P. A. Glans, T. Learmonth, K. E. Smith, J. Guo and N. M. GHarrison, Phys. Rev. B, 2008, 77, 155115.

[56] M. van Schilfgaarde, T. Kotani and S. Faleev, Phys. Rev. Lett., 2006, 96, 226402.

[57] P. Cortona and M. Mebarki, J. Phys.-Cond. Mat., 2011, 23, 8.

[58] A. B. Gordienko, Y. N. Zhuravlev and D. G. Fedorov, Phys. Sol. State, 2007, 49, 223.

[59] X. L. Nie, S. H. Wei and S. B. Zhang, Phys. Rev. B, 2002, 65, 075111.

[60] M. Heinemann, B. Eifert and C. Heiliger, Phys. Rev. B, 2013, 87, 5.

[61] F. Tran and P. Blaha, Phys. Rev. B, 2011, 83, 235118.

[62] L. Y. Isseroff and E. A. Carter, Phys. Rev. B, 2012, 85, 235142.

[63] D. Le, S. Stolbov and T. S. Rahman, Surf. Sci., 2009, 603, 1637.

[64] A. Soon, T. Sohnel and H. Idriss, Surf. Sci., 2005, 579, 131.

[65] D. O. Scanlon, B. J. Morgan, G. W. Watson and A. Walsh, Phys. Rev. Lett., 2009, 103, 096405.

[66] F. Bruneval, N. Vast, L. Reining, M. Izquierdo, F. Sirotti and N. Barrett, Phys. Rev. Lett., 2006, 97, 4.

[67] T. Kotani, M. van Schilfgaarde and S. V. Faleev, Phys. Rev. B, 2007, 76, 165106.

[68] S. Lany, Phys. Rev. B, 2013, 87, 085112.

[69] C. Noguera, J. Phys. Cond. Mat., 2000, 12, R367.

[70] K. H. Schulz and D. F. Cox, Phys. Rev. B, 1991, 43, 1610.

[71] M. M. Islam, B. Diawara, V. Maurice and P. Marcus, Surf. Sci., 2010, 604, 1516.

[72] M. A. Nygren, L. G. M. Pettersson, A. Freitag, V. Staemmler, D. H. Gay and A. L. Rohl, J. Phys. Chem., 1996, 100, 294.

[73] N. D. McClenaghan, P. J. Hu and C. Hardacre, Surf. Sci., 2000, 464, 223.

[74] M. M. Islam, B. Diawara, V. Maurice and P. Marcus, Surf. Sci., 2009, 603, 2087.

[75] M. Li, J. Y. Zhang, Y. Zhang, G. F. Zhang and T. M. Wang, Appl. Surf. Sci., 2011, 257, 10710.

[76] C. Li, F. Wang, S. F. Li, Q. Sun and Y. Jia, Phys. Lett. A, 2010, 374, 2994.

[77] A. Soon, M. Todorova, B. Delley and C. Stampfl, Phys. Rev. B, 2007, 75, 125420.

[78] A. Soon, M. Todorova, B. Delley and C. Stampfi, Surf. Sci., 2007, 601, 5809.

[79] K. Reuter and M. Scheffler, Phys. Rev. B, 2002, 65, 035406.

[80] A. T. Lozovoi, A. Alavi and M. W. Finnis, Comp. Phys. Comm., 2001, 137, 174. 
[81] S. Asbrink and L. J. Norrby, Acta Crystallogr. Sec. B, 1970, B 26, 8.

[82] S. C. Ray, Sol. En. Mat. And Sol. Cells, 2001, 68, 307.

[83] K. L. Hardee and A. J. Bard, J. Electrochem. Soc., 1977, 124, 215.

[84] F. P. Koffyberg and F. A. Benko, J. Appl. Phys., 1982, 53, 1173.

[85] F. Marabelli, G. B. Parravicini and F. Salghettidrioli, Phys. Rev. B, 1995, 52, 1433.

[86] J. B. Forsyth, P. J. Brown and B. M. Wanklyn, J. Phys. C, 1988, 21, 2917.

[87] B. X. Yang, J. M. Tranquada and G. Shirane, Phys. Rev. B, 1988, 38, 174.

[88] P. J. Brown, T. Chattopadhyay, J. B. Forsyth, V. Nunez and F. Tasset, J. Phys.-Cond. Mat., $1991,3,4281$.

[89] M. Ain, A. Menelle, B. M. Wanklyn and E. F. Bertaut, J. Phys.-Cond. Mat., 1992, 4, 5327.

[90] Y. Peng, Z. Zhang, T. V. Pham, Y. Zhao, P. Wu and J. L. Wang, J. Appl. Phys., 2012, 111, 5.

[91] L. Debbichi, M. C. M. de Lucas, J. F. Pierson and P. Kruger, J. Phys. Chem. C, 2012, $116,10232$.

[92] J. Hu, D. D. Li, J. G. Lu and R. Q. Wu, J. Phys. Chem. C, 2010, 114, 17120.

[93] D. X. Wu, Q. M. Zhang and M. Tao, Phys. Rev. B, 2006, 73, 6.

[94] W. Reichardt, F. Gompf, M. Ain and B. M. Wanklyn, Zeitschrift Fur Physik B, 1990, 81, 19.

[95] M. A. Dar, Q. Ahsanulhaq, Y. S. Kim, J. M. Sohn, W. B. Kim and H. Shin, Appl. Surf. Sci., $2009,255,6279$.

[96] X. K. Chen, J. C. Irwin and J. P. Franck, Phys. Rev. B, 1995, 52, 13130.

[97] G. Kliche and Z. V. Popovic, Phys. Rev. B, 1990, 42, 10060.

[98] V. I. Anisimov, J. Zaanen and O. K. Andersen, Phys. Rev. B, 1991, 44, 943.

[99] C. E. Ekuma, A. V. I., M. J. and J. M., Europ. Phys. J. B, 2014, 87, 23.

[100] P. Jiang, D. Prendergast, F. Borondics, S. Porsgaard, L. Giovanetti, E. Pach, J. Newberg, H. Bluhm, F. Besenbacher and M. Salmeron, J. Chem. Phys., 2013, 138, 024704.

[101] M. Nolan and S. D. Elliott, Phys. Chem. Chem. Phys., 2006, 8, 5350.

[102] A. Svane and O. Gunnarsson, Phys. Rev. Lett., 1990, 65, 1148.

[103] Z. Szotek, W. M. Temmerman and H. Winter, Phys. Rev. B, 1993, 47, 4029.

[104] J. F. Pierson, A. Thobor-Keck and A. Billard, Appl. Surf. Sci., 2003, 210, 359.

[105] S. L. Dudarev, G. A. Botton, S. Y. Savrasov, C. J. Humphreys and A. P. Sutton, Phys. Rev. B, $1998,57,1505$.

[106] Q. Zhang, K. Zhang, D. Xu, G. Yang, H. Huang, F. Nie, C. Liu and S. Yang, Progr. Mat. Sci., 2014, 60, 208.

[107] S. Warren, W. R. Flavell, A. G. Thomas, J. Hollingworth, P. L. Wincott, A. F. Prime, S. Downes and C. K. Chen, J. Phys.-Cond. Mat., 1999, 11, 5021.

[108] Y. Maimaiti, M. Nolan and S. D. Elliott, Phys. Chem. Chem. Phys., 2014, 16, 3036.

[109] M. Monte, D. Gamarra, A. Lopez Camara, S. B. Rasmussen, N. Gyorffy, Z. Schay, A. Martinez-Arias and J. C. Conesa, Catalysis Today, 2014, 229, 104.

[110] F. Jensen, F. Besenbacher and I. Stensgaard, Surf. Sci., 1992, 269, 400.

[111] S. M. Johnston, A. Mulligan, V. Dhanak and M. Kadodwala, Surf. Sci., 2002, 519, 57.

[112] Z. Crljen, P. Lazic, D. Sokcevic and R. Brako, Phys. Rev. B, 2003, 68, 195411. 
[113] K. Heinemann, D. B. Rao and D. L. Douglass, Oxid. Met., 1975, 9, 379.

[114] L. H. Dubois, Surf. Sci., 1982, 119, 399.

[115] J. C. Yang, M. Yeadon, B. Kolasa and J. M. Gibson, Microsc. and Microanal., 1998, 4, 334.

[116] K. Lahtonen, M. Hirsimaki, M. Lampimaki and M. Valden, J. Chem. Phys., 2008, 129, 124703.

[117] C. P. Leon, C. Surgers and H. von Lohneysen, Phys. Rev. B, 2012, 85, 035434.

[118] M. Lee and A. J. H. McGaughey, Phys. Rev. B, 2011, 83, 165447.

[119] G. W. Zhou, L. Luo, L. Li, J. Ciston, E. A. Stach and J. C. Yang, Phys. Rev. Lett., 2012, 109, 235502.

[120] P. J. Rous, in Cohesion and Structure of Surfaces, ed. F. de Boer and D. Pettifor, North-Holland, 1995, vol. 4, p. 1.

[121] F. Besenbacher and J. K. Nørskov, Progr. Surf. Sci., 1993, 44, 5.

[122] C. Q. Sun, Surf. Rev. Lett., 2001, 8, 367.

[123] T. Lederer, D. Arvanitis, G. Comelli, L. Troger and K. Baberschke, Phys. Rev. B, 1993, 48, 15390.

[124] M. Alatalo, S. Jaatinen, P. Salo and K. Laasonen, Phys. Rev. B, 2004, 70, 6.

[125] W. K. Chen, C. H. Lu, Z. H. Chen, Y. Li and J. Q. Li, Chin. J. Chem. Phys., 2006, $19,54$.

[126] X. Duan, O. Warschkow, A. Soon, B. Delley and C. Stampfl, Phys. Rev. B, 2010, 81, 075430.

[127] K. Yagyu, X. Liu, Y. Yoshimoto, K. Nakatsuji and F. Komori, J. Phys. Chem. C, 2009, $113,5541$.

[128] A. Puisto, H. Pitkanen, M. Alatalo, S. Jaatinen, P. Salo, A. S. Foster, T. Kangas and K. Laasonen, Catalysis Today, 2005, 100, 403.

[129] M. K. Rajumon, K. Prabhakaran and C. N. R. Rao, Surf. Sci., 1990, 233, L237.

[130] A. Spitzer and H. Luth, Surf. Sci., 1982, 118, 136.

[131] T. Yokoyama, D. Arvanitis, T. Lederer, M. Tischer, L. Troger, K. Baberschke and G. Comelli, Phys. Rev. B, 1993, 48, 15405.

[132] T. Katayama, D. Sekiba, K. Mukai, Y. Yamashita, F. Komori and J. Yoshinobu, J. Phys. Chem. C, 2007, 111, 15059 .

[133] T. Fujita, Y. Okawa, Y. Matsumoto and K. Tanaka, Phys. Rev. B, 1996, 54, 2167.

[134] D. Arvanitis, G. Comelli, T. Lederer, H. Rabus and K. Baberschke, Chem. Phys. Lett., 1993, $211,53$.

[135] M. Sotto, Surf. Sci., 1992, 260, 235.

[136] M. Kittel, M. Polcik, R. Terborg, J. T. Hoeft, P. Baumgartel, A. M. Bradshaw, R. L. Toomes, J. H. Kang, D. P. Woodruff, M. Pascal, C. L. A. Lamont and E. Rotenberg, Surf. Sci., 2001, 470, 311.

[137] H. C. Zeng, R. A. Mcfarlane and K. A. R. Mitchell, Surf. Sci., 1989, 208, L7.

[138] F. Jensen, F. Besenbacher, E. Laegsgaard and I. Stensgaard, Phys. Rev. B, 1990, 42, 9206.

[139] C. Woll, R. J. Wilson, S. Chiang, H. C. Zeng and K. A. R. Mitchell, Phys. Rev. B, 1990, $42,11926$.

[140] F. M. Leibsle, Surf. Sci., 1995, 337, 51.

[141] M. Yata, H. Rouch and K. Nakamura, Phys. Rev. B, 1997, 56, 10579.

[142] M. Wuttig, R. Franchy and H. Ibach, Surf. Sci., 1989, 213, 103.

[143] M. Wuttig, R. Franchy and H. Ibach, Surf. Sci., 1989, 224, L979.

[144] I. K. Robinson, E. Vlieg and S. Ferrer, Phys. Rev. B, 1990, 42, 6954. 
[145] W. Liu, K. C. Wong, H. C. Zeng and K. A. R. Mitchell, Progr. in Surf. Sci., 1995, 50, 247.

[146] N. Bonini, A. Kokalj, A. Dal Corso, S. de Gironcoli and S. Baroni, Surf. Sci., 2006, 600, 5074.

[147] K. Tanaka, Y. Matsumoto, T. Fujita and Y. Okawa, Appl. Surf. Sci., 1998, 130, 475.

[148] H. Iddir, D. D. Fong, P. Zapol, P. H. Fuoss, L. A. Curtiss, G. W. Zhou and J. A. Eastman, Phys. Rev. B, 2007, 76, 241404.

[149] W. A. Saidi, M. Lee, L. Li, G. W. Zhou and A. J. H. McGaughey, Phys. Rev. B, 2012, 86, 245429.

[150] M. J. Harrison, D. P. Woodruff, J. Robinson, D. Sander, W. Pan and J. Kirschner, Phys. Rev. B, 2006, 74, 165402.

[151] K. Tanaka, T. Fujita and Y. Okawa, Surf. Sci., 1998, 401, L407.

[152] S. Jaatinen, M. Rusanen and P. Salo, Surf. Sci., 2007, 601, 1813.

[153] S. Jaatinen, J. Blomqvist, P. Salo, A. Puisto, M. Alatalo, M. Hirsimaki, M. Ahonen and M. Valden, Phys. Rev. B, $2007, \mathbf{7 5}, 8$.

[154] E. A. Colbourn and J. E. Inglesfield, Phys. Rev. Lett., 1991, 66, 2006.

[155] S. Stolbov and T. S. Rahman, J. Chem. Phys., 2002, 117, 8523.

[156] S. Stolbov and T. S. Rahman, Phys. Rev. Lett., 2002, 89, 116101.

[157] S. Stolbov, A. Kara and T. S. Rahman, Phys. Rev. B, 2002, 66, 245405.

[158] I. Merrick, J. E. Inglesfield and H. Ishida, Surf. Sci., 2004, 551, 158.

[159] T. Kangas and K. Laasonen, Surf. Sci., 2012, 606, 192.

[160] M. Lee and A. J. H. McGaughey, Surf. Sci., 2010, 604, 1425.

[161] G. W. Zhou, L. Luo, L. Li, J. Ciston, E. A. Stach, W. A. Saidi and J. C. Yang, Chem. Comm., $2013,49,10862$.

[162] L. D. Sun, M. Hohage, R. Denk and P. Zeppenfeld, Phys. Rev. B, 2007, 76, 245412.

[163] R. Feidenshansl, F. Grey, R. L. Johnson, S. G. J. Mochrie, J. Bohr and M. Nielsen, Phys. Rev. B, $1990,41,5420$.

[164] S. R. Parkin, H. C. Zeng, M. Y. Zhou and K. A. R. Mitchell, Phys. Rev. B, 1990, 41, 5432.

[165] L. D. Sun, M. Hohage and P. Zeppenfeld, Phys. Rev. B, 2004, 69, 045407.

[166] G. Ertl, Surf. Sci., 1967, 6, 208.

[167] S. Kishimoto, M. Kageshima, Y. Naitoh, Y. J. Li and Y. Sugawara, Surf. Sci., 2008, 602, 2175.

[168] R. Feidenhansl, F. Grey, M. Nielsen, F. Besenbacher, F. Jensen, E. Laegsgaard, I. Stensgaard, K. W. Jacobsen, J. K. Nórskov and R. L. Johnson, Phys. Rev. Lett., 1990, 65, 2027.

[169] D. Coulman, J. Wintterlin, J. V. Barth, G. Ertl and R. J. Behm, Surf. Sci., 1990, 240, 151.

[170] G. Dorenbos, M. Breeman and D. O. Boerma, Phys. Rev. B, 1993, 47, 1580.

[171] W. Liu, K. C. Wong and K. A. R. Mitchell, Surf. Sci., 1995, 339, 151.

[172] Q. Liu, L. Li, N. Cai, W. A. Saidi and G. W. Zhou, Surf. Sci., 2014, 627, 75.

[173] A. F. Carley, P. R. Davies and M. W. Roberts, Phil. Trans. Royal Soc. A, 2005, 363, 829.

[174] D. Coulman, J. Wintterlin, J. V. Barth, G. Ertl and R. J. Behm, Surf. Sci., 1990, 240, 151.

[175] F. M. Chua, Y. Kuk and P. J. Silverman, Phys. Rev. Lett., 1989, 63, 386.

[176] Y. Kuk, F. M. Chua, P. J. Silverman and J. A. Meyer, Phys. Rev. B, 1990, 41, 12393. 
[177] D. Mocuta, J. Ahner, J. G. Lee, S. Denev and J. T. Yates, Surf. Sci., 1999, 436, 72.

[178] L. Li, N. Cai, W. A. Saidi and G. W. Zhou, Chem. Phys. Lett., 2014, 613, 64.

[179] K. W. Jacobsen and J. K. Norskov, Phys. Rev. Lett., 1990, 65, 1788.

[180] S. Y. Liem, G. Kresse and J. H. R. Clarke, Surf. Sci., 1998, 415, 194.

[181] K. Kern, H. Niehus, A. Schatz, P. Zeppenfeld, J. George and G. Comsafguif, Phys. Rev. Lett., 1991, 67, 855.

[182] G. W. Zhou and J. C. Yang, Surf. Sci., 2003, 531, 359.

[183] N. Blanchard, D. Martin and P. Weightman, Phys. Stat. Sol. C - Conferences and Critical Reviews, 2005, p. 4017.

[184] J. Buisset, H. P. Rust, E. K. Schweizer, L. Cramer and A. M. Bradshaw, Surf. Sci., 1996, 349, L147.

[185] D. Vanderbilt, Surf. Sci., 1992, 268, L300.

[186] P. Zeppenfeld, M. Krzyzowski, C. Romainczyk, G. Comsa and M. G. Lagally, Phys. Rev. Lett., $1994,72,2737$.

[187] G. Prevot, B. Croset, Y. Girard, A. Coati, Y. Garreau, M. Hohage, L. D. Sun and P. Zeppenfeld, Surf. Sci., 2004, $\mathbf{5 4 9}, 52$.

[188] K. Berge and A. Goldmann, Surf. Sci., 2003, 540, 97.

[189] K. Bobrov and L. Guillemot, Phys. Rev. B, 2008, 78, 121408.

[190] J. Harl and G. Kresse, Surf. Sci., 2006, 600, 4633.

[191] L. Guillemot and K. Bobrov, Phys. Rev. B, 2011, 83, 075409.

[192] F. Frechard and R. A. van Santen, Surf. Sci., 1998, 407, 200.

[193] S. Y. Liem, J. H. R. Clarke and G. Kresse, Surf. Sci., 2000, 459, 104.

[194] J. Bamidele, J. Brndiar, A. Gulans, L. Kantorovich and I. Stich, J. Chem. Theo. Comp., 2013, 9, 5578.

[195] R. A. Didio, D. M. Zehner and E. W. Plummer, J. Vac. Sci. Tech. A, 1984, 2, 852.

[196] P. Cortona and C. Sapet, Surf. Sci., 2005, 585, 155.

[197] R. Courths, B. Cord, H. Wern, H. Saalfeld and S. Hufner, Sol. State Comm., 1987, 63, 619.

[198] R. Matzdorf and A. Goldmann, Surf. Sci., 1998, 412, 61.

[199] P. Cabrera-Sanfelix, C. Lin, A. Arnau and D. Sanchez-Portal, J. Phys.-Cond. Mat., 2013, 25, 135003.

[200] F. Pforte, A. Gerlach, A. Goldmann, R. Matzdorf, J. Braun and A. Postnikov, Phys. Rev. B, $2001,63,165405$.

[201] L. Li and G. W. Zhou, Surf. Sci., 2013, 615, 57.

[202] G. W. Simmons, D. F. Mitchell and K. R. Lawless, Surf. Sci., 1967, 8, 130.

[203] J. H. Ho and R. W. Vook, J. Crys. Growth, 1978, 44, 561.

[204] H. Niehus, Surf. Sci., 1983, 130, 41.

[205] J. Haase and H. J. Kuhr, Surf. Sci., 1988, 203, L695.

[206] B. Luo and J. Urban, J. Phys. - Cond. Matt., 1991, 3, 2873.

[207] F. Jensen, F. Besenbacher, E. Laegsgaard and I. Stensgaard, Surf. Sci., 1991, 259, L774.

[208] W. E. J. Vankooten, O. L. J. Gijzeman and J. W. Geus, Surf. Sci., 1993, 280, L243.

[209] T. Matsumoto, R. A. Bennett, P. Stone, T. Yamada, K. Domen and M. Bowker, Surf. Sci., 2001, 471, 225. 
[210] F. Wiame, V. Maurice and P. Marcus, Surf. Sci., 2007, 601, 1193.

[211] W. Jacob, V. Dose and A. Goldmann, Appl. Phys. A, 1986, 41, 145.

[212] Y. Xu and M. Mavrikakis, Surf. Sci., 2001, 494, 131.

[213] M. L. C., Z. J. M. and X. K. W., Science China-Phys. Mech. Astron., 2013, 56, 573.

[214] X. Y. Pang, L. Q. Xue and G. C. Wang, Langmuir, 2007, 23, 4910.

[215] R. W. Judd, P. Hollins and J. Pritchard, Surf. Sci., 1986, 171, 643.

[216] R. L. Toomes, D. P. Woodruff, M. Polcik, S. Bao, P. Hofmann and K. M. Schindler, Surf. Sci., $2000,445,300$.

[217] A. Michaelides, K. Reuter and M. Scheffler, J. Vac. Sci. Tech. A, 2005, 23, 1487.

[218] J. Schnadt, A. Michaelides, J. Knudsen, R. T. Vang, K. Reuter, E. Lægsgaard, M. Scheffler and F. Besenbacher, Phys. Rev. Lett., 2006, 96, 146101.

[219] M. Todorova, K. Reuter and M. Scheffler, J. Phys. Chem. B, 2004, 108, 14477.

[220] C. Stampfl, Catal. Tod., 2005, 105, 17-35.

[221] J. Gustafson, A. Mikkelsen, M. Borg, E. Lundgren, L. Kohler, G. Kresse, M. Schmid, P. Varga, J. Yuhara, X. Torrelles, C. Quiros and J. N. Andersen, Phys. Rev. Lett., 2004, 92, 126102.

[222] L. Kohler, G. Kresse, M. Schmid, E. Lundgren, J. Gustafson, A. Mikkelsen, M. Borg, J. Yuhara, J. N. Andersen, M. Marsman and P. Varga, Phys. Rev. Lett., 2004, 93, 266103.

[223] A. Michaelides, M. L. Bocquet, P. Sautet, A. Alavi and D. A. King, Chem. Phys. Lett., $2003,367,344$.

[224] M. Todorova, K. Reuter and M. Scheffler, Phys. Rev. B, 2005, 71, 195403.

[225] J. A. Eastman, P. H. Fuoss, L. E. Rehn, P. M. Baldo, G. W. Zhou, D. D. Fong and L. J. Thompson, App. Phys. Lett., 2005, 87, 051914.

[226] J. F. Pierson, D. Wiederkehr and A. Billard, Thin Solid Films, 2005, 478, 196.

[227] D. A. Goulden, Phil. Mag., 1976, 33, 393.

[228] F. W. Young, J. V. Cathcart and A. T. Gwathmey, Acta Metall., 1956, 4, 145.

[229] A. T. Gwathmey and A. F. Benton, J. of Phys. Chem., 1942, 46, 969.

[230] T. N. Rhodin, J. Am. Chem. Soc., 1950, 72, 5102.

[231] L. O. Brockway and I. M. Adler, J. Electrochem. Soc., 1972, 119, 899.

[232] R. H. Milne and A. Howie, Phil. Mag. A, 1984, 49, 665.

[233] J. C. Yang, M. Yeadon, B. Kolasa and J. M. Gibson, App. Phys. Lett., 1997, 70, 3522.

[234] J. C. Yang, M. Yeadon, B. Kolasa and J. M. Gibson, Scr. Mat., 1998, 38, 1237.

[235] J. C. Yang, D. Evan and L. Tropia, App. Phys. Lett., 2002, 81, 241.

[236] P. Stefanov and T. Marinova, Appl. Surf. Sci., 1988, 31, 445.

[237] G. W. Zhou, Acta Mat., 2009, 57, 4432.

[238] G. W. Zhou and J. C. Yang, Applied Surf. Sci., 2003, 210, 165.

[239] G. W. Zhou, W. S. Slaughter and J. C. Yang, Phys. Rev. Lett., 2005, 94, 246101.

[240] J. Tersoff and R. M. Tromp, Phys. Rev. Lett., 1993, 70, 2782.

[241] M. Lampimaki, K. Lahtonen, M. Hirsimaki and M. Valden, J. Chem. Phys., 2007, 126, 034703. 
[242] J. C. Yang, M. D. Bharadwaj, G. W. Zhou and L. Tropia, Microsc. and Microanal., 2001, 7, 486.

[243] X. Bao, M. Muhler, B. Pettinger, Y. Uchida, G. Lehmpfuhl, R. Schlogl and G. Ertl, Catal. Lett., $1995,32,171$.

[244] A. Bottcher and H. Niehus, J. Chem. Phys., 1999, 110, 3186.

[245] T. Kangas and K. Laasonen, Surf. Sci., 2008, 602, 3239.

[246] T. Kangas, K. Laasonen, A. Puisto, H. Pitkanen and M. Alatalo, Surf. Sci., 2005, 584, 62.

[247] M. Y. Lee and J. H. McGaughey, Surf. Sc., 2009, 603, 3404.

[248] M. Alatalo, A. Puisto, H. Pitkanen, A. S. Foster and K. Laasonen, Surf. Sci., 2006, 600, 1574.

[249] M. Ahonen, M. Hirsimaki, A. Puisto, S. Auvinen, M. Valden and M. Alatalo, Chem. Phys. Lett., $2008,456,211$.

[250] P. Junell, M. Ahonen, M. Hirsimaki and M. Valden, Surf. Rev. and Lett., 2004, 11, 457.

[251] B. Devine, T. R. Shan, Y. T. Cheng, A. J. McGaughey, M. Y. Lee, S. Phillpot and S. B. Sinnot, Phys.Rev.B, 2011, 84, 125308.

[252] A. Laio and M. Parrinello, Proc. Nat. Acad. Sc., 2002, 99, 12562.

[253] J. C. Yang, B. Kolasa, J. M. Gibson and M. Yeadon, App. Phys. Lett., 1998, 73, 2841.

[254] J. C. Yang, M. Yeadon, B. Kolasa and J. M. Gibson, J. Electrochem. Soc., 1999, 146, 2103.

[255] G. W. Zhou, L. Wang and J. C. Yang, J. Appl. Phys., 2005, 97, 063509.

[256] G. W. Zhou and J. C. Yang, J. Mat. Res., 2005, 20, 1684.

[257] G. W. Zhou and J. C. Yang, Applied Surf. Sci., 2004, 222, 357.

[258] G. W. Zhou and J. C. Yang, Surf. Sci., 2004, 559, 100.

[259] G. W. Zhou and J. C. Yang, Phys. Rev. Lett., 2002, 89, 4.

[260] G. W. Zhou, App. Phys. Lett., 2009, 94, 233115.

[261] G. W. Zhou, X. D. Chen, D. Gallagher and J. C. Yang, App. Phys. Lett., 2008, 93, 3.

[262] K. R. Lawless and A. T. Gwathmey, Acta Metall., 1956, 4, 153.

[263] M. Rauh and P. Wissmann, Thin Solid Films, 1993, 228, 121.

[264] P. A. Mulheran and J. A. Blackman, Phil. Mag. Lett., 1995, 72, 55.

[265] M. C. Bartelt and J. W. Evans, Phys. Rev. B, 1996, 54, R17359.

[266] W. H. Orr, J. Electrochem. Soc., 1964, 111, C184.

[267] P. H. Holloway and J. B. Hudson, Surf. Sci., 1974, 43, 123.

[268] A. N. Kolmogorov, Bull. Acad. Sci. URSS, 1937, 3, 355.

[269] M. Avrami, J. Chem. Phys., 1939, 7, 1103.

[270] W. A. Johnson and R. F. Mehl, Trans. Am. Inst. Mining And Metal. Eng., 1939, 135, 416.

[271] B. Jeon, S. K. R. S. Sankaranarayanan, A. C. T. van Duin and S. Ramanathan, Phil. Mag., $2011,91,4073$.

[272] H. Leidheiser, The corrosion of copper, tin, and their alloys, Wiley, 1971.

[273] A. Ronnquist and H. Fischmeister, J. Inst. Met., 1960, 89, 65.

[274] T. N. Rhodin, J. Am. Chem. Soc., 1951, 73, 3143. 
[275] L. Bouzidi and A. J. Slavin, Surf. Sci., 2005, 580, 195.

[276] J. W. Lim, Y. Ishikawa, K. Miyake, M. Yamashita and M. Isshiki, Mat. Trans., 2002, 43, 1403.

[277] P. T. Landsberg, J. Chem. Phys., 1955, 23, 1079.

[278] T. B. Grimley and B. M. W. Trapnell, Proc. Royal Soc. A, 1956, 234, 405.

[279] H. H. Uhlig, Acta Metall., 1956, 4, 541.

[280] U. R. Evans, Trans. Electrochem. Soc., 1947, 91, 547.

[281] N. Cabrera and N. F. Mott, Rep. Prog. Phys., 1948, 12, 163.

[282] Y. Z. Hu, R. Sharangpani and S. P. Tay, J. Vac. Sci. Tech. A-Vac. Surf. and Films, 2000, $18,2527$.

[283] S. K. Roy and S. C. Sircar, Oxid. Met., 1981, 15, 9.

[284] H. Derin and K. Kantarli, Appl. Phys. A, 2002, 75, 391.

[285] R. vanWijk, O. L. J. Gijzeman and J. W. Geus, Applied Surf. Sci., 1996, 93, 237.

[286] A. Njeh, T. Wieder and H. Fuess, Surf. Interf. Anal., 2002, 33, 626.

[287] A. Manara, V. Sirtori and L. Mammarella, Surf. Interf. Anal., 1992, 18, 32.

[288] K. Fujita, D. Ando, M. Uchikoshi, K. Mimura and M. Isshiki, Appl. Surf. Sci., 2013, $276,347$.

[289] M. O'Reilly, X. Jiang, J. T. Beechinor, S. Lynch, C. N. Nidheasuna, J. C. Patterson and G. M. Crean, Appl. Surf. Sci., 1995, 91, 152.

[290] W. Gao, H. Gong, J. He, A. Thomas, L. Chan and S. Li, Mat. Lett., 2001, 51, 78.

[291] P. Keil, R. Frahm and D. Lutzenkirchen-Hecht, Corr. Sci., 2010, 52, 1305.

[292] P. Keil, D. Lutzenkirchen-Hecht and R. Frahm, 13th International Conference on X-Ray Absorption Fine Structure (XAFS13), Melville, 2007, p. 490.

[293] S. K. Chawla, B. I. Rickett, N. Sankarraman and J. H. Payer, Corr. Sci., 1992, 33, 1617.

[294] Y. S. Chu, I. K. Robinson and A. A. Gewirth, J. Chem. Phys., 1999, 110, 5952.

[295] S. Suzuki, Y. Ishikawa, M. Isshiki and Y. Waseda, Mat. Trans. Jim, 1997, 38, 1004.

[296] V. Rico, A. Borrás, F. Yubero, J. P. Espinós, F. Frutos and A. R. González-Elipe, J. Phys. Chem. C, 2009, 113, 3775 .

[297] I. Platzman, C. Saguy, R. Brener, R. Tannenbaum and H. Haick, Langmuir, 2010, $26,191$.

[298] S. Yamamoto, H. Bluhm, K. Andersson, G. Ketteler, H. Ogasawara, M. Salmeron and A. Nilsson, J. Phys.-Cond. Mat., 2008, 20, 14 .

[299] F. M. Ross and J. M. Gibson, Phys. Rev. Lett., 1992, 68, 1782.

[300] G. Dujardin, A. Mayne, G. Comtet, L. Hellner, M. Jamet, E. LeGoff and P. Millet, Phys. Rev. Lett., 1996, 76, 3782 .

[301] K. Thurmer, E. Williams and J. Reutt-Robey, Science, 2002, 297, 2033.

[302] G. Dujardin, A. J. Mayne and F. Rose, Phys. Rev. Lett., 1999, 82, 3448.

[303] A. J. Mayne, F. Rose and G. Dujardin, Surf. Sci., 2003, 523, 157.

[304] Y. F. Zhu, K. Mimura, J. W. Lim, M. Isshiki and Q. Jiang, Metall. Mat. Trans. A, 2006, 37A, 1231.

[305] V. V. Belousov and A. A. Klimashin, Russ. Chem. Rev., 2013, 82, 273. 
[306] J. E. Boggio, J. Chem. Phys., 1979, 70, 5054.

[307] R. Courths, S. Hufner, P. Kemkes and G. Wiesen, Surf. Sci., 1997, 376, 43.

[308] T. Schimizu and M. Tsukada, Surf. Sci., 1993, 295, L1017.

[309] M. Forster, R. Raval, J. Carrasco, A. Michaelides and A. Hodgson, Chem. Sc., 2012, 3, 93.

[310] C. X. Kronawitter, C. Riplinger, X. B. He, P. Zahl, E. A. Carter, P. Sutter and B. E. Koel, J. Am. Chem. Soc., 2014, 136, 13283.

[311] X. Y. Deng, A. Verdaguer, T. Herranz, C. Weis, H. Bluhm and M. Salmeron, Lang., 2008, $24,9474$.

[312] P. Jiang, J. L. Chen, F. Borondics, P. A. Glans, M. W. West, C. L. Chang, M. Salmeron and J. H. Guo, Elec. Comm., 2010, 12, 820.

[313] M. DellAngela, T. Anniyev, M. Beye, R. Coffee, A. Foehlisch, J. Gladh, T. Katayama, S. Kaya, O. Krupin, J. LaRue, A. Møgelhøj, D. Nordlund, J. K. Nørskov, H. Öberg, H. Ogasawara, H. ÖstrÖm, L. G. M. Pettersson, W. F. Schlotter, J. A. Sellberg, F. Sorgenfrei, J. J. Turner, M. Wolf, W. Wurth and A. Nilsson, Science, 2013, 339, 1302.

[314] J. Schnadt, J. Knudsen, J. N. Andersen, H. Siegbahn, A. Pietzsch, F. Hennies, N. Johansson, N. Mårtensson, G. Öhrwall, S. Bahr, S. Mähl and O. Schaff, Journal of Synchrotron Radiation, 2012, 19, 701. 